\title{
Stem Cells for Cartilage Repair: Preclinical Studies and Insights in Translational Animal Models and Outcome Measures
}

\author{
Melissa Lo Monaco (iD, ${ }^{1,2}$ Greet Merckx (iD), Jessica Ratajczak, ${ }^{1}$ Pascal Gervois, ${ }^{1}$ \\ Petra Hilkens $\mathbb{D}^{1}{ }^{1}$ Peter Clegg, ${ }^{3}$ Annelies Bronckaers, ${ }^{1}$ Jean-Michel Vandeweerd, ${ }^{2}$ \\ and Ivo Lambrichts ${ }^{1}$ \\ ${ }^{1}$ Department of Morphology, Biomedical Research Institute, Faculty of Medicine and Life Sciences, Hasselt University, \\ Campus Diepenbeek, 3590 Diepenbeek, Belgium \\ ${ }^{2}$ Department of Veterinary Medicine, Integrated Veterinary Research Unit-Namur Research Institute for Life Science (IVRU-NARILIS), \\ Faculty of Sciences, University of Namur, 5000 Namur, Belgium \\ ${ }^{3}$ Department of Musculoskeletal Biology, Faculty of Health and Life Sciences, University of Liverpool, Leahurst Campus, \\ Neston CH64 7TE, UK
}

Correspondence should be addressed to Melissa Lo Monaco; melissa.lomonaco@uhasselt.be

Received 27 July 2017; Revised 29 November 2017; Accepted 10 December 2017; Published 5 February 2018

Academic Editor: Celeste Scotti

Copyright (c) 2018 Melissa Lo Monaco et al. This is an open access article distributed under the Creative Commons Attribution License, which permits unrestricted use, distribution, and reproduction in any medium, provided the original work is properly cited.

Due to the restricted intrinsic capacity of resident chondrocytes to regenerate the lost cartilage postinjury, stem cell-based therapies have been proposed as a novel therapeutic approach for cartilage repair. Moreover, stem cell-based therapies using mesenchymal stem cells (MSCs) or induced pluripotent stem cells (iPSCs) have been used successfully in preclinical and clinical settings. Despite these promising reports, the exact mechanisms underlying stem cell-mediated cartilage repair remain uncertain. Stem cells can contribute to cartilage repair via chondrogenic differentiation, via immunomodulation, or by the production of paracrine factors and extracellular vesicles. But before novel cell-based therapies for cartilage repair can be introduced into the clinic, rigorous testing in preclinical animal models is required. Preclinical models used in regenerative cartilage studies include murine, lapine, caprine, ovine, porcine, canine, and equine models, each associated with its specific advantages and limitations. This review presents a summary of recent in vitro data and from in vivo preclinical studies justifying the use of MSCs and iPSCs in cartilage tissue engineering. Moreover, the advantages and disadvantages of utilizing small and large animals will be discussed, while also describing suitable outcome measures for evaluating cartilage repair.

\section{Introduction}

Articular cartilage covers the ends of the bone; due to its slightly compressible and elastic nature and lubricated surface, it provides the joint with shock absorption and lubrication $[1,2]$. Hyaline cartilage is comprised of $95 \%$ extracellular matrix (ECM) (dry weight) and only $5 \%$ of sparsely distributed chondrocytes [3]. This matrix primarily consists of type II collagen and proteoglycans (PGs). Negatively charged glycoproteins are able to attract water, allowing the cartilage to resist compressive forces [4]. Despite the fact that chondrocytes only make up about $5 \%$ of hyaline cartilage tissue, they are integral for cartilage function and homeostasis [4]. These cells are of mesenchymal origin and are responsible for synthesizing cartilage ECM [3]. Hyaline cartilage is an avascular tissue which, in part, explains the limited regeneration capacity following injury. The lack of vasculature makes it difficult for progenitor cells to be recruited to the site of injury and hinders the supply of nutrients necessary for tissue regeneration $[1,5]$.

Cartilage loss can occur as a consequence of traumatic injury, leading to focal defects or through chronic degeneration. Both partial thickness and full thickness cartilage defects occur [6]. Since full thickness lesions extend into the subchondral bone, they have access to bone marrow cells and therefore have a higher probability of spontaneous regeneration than partial thickness lesions, which only 
involve the avascular cartilage tissue [6]. Eventually, cartilage defects will lead to activity-related pain, swelling, and decreased mobility and will frequently progress to osteoarthritis [1, 7]. In the United States alone, over 27 million adults suffer from osteoarthritis, leading to a substantive clinical and financial burden $[8,9]$.

There are currently no drugs available to effectively heal cartilage defects. When cartilage defects develop into osteoarthritis, the condition can only be managed by a multidisciplinary approach including pharmacotherapy, physiotherapy, or joint replacement surgery [10]. However, several surgical interventions can be performed in order to prevent progression towards osteoarthritis [1]. Current techniques include arthroscopic lavage and debridement, microfracture induction, and autologous chondrocyte implantation [11]. Although these techniques have been proposed to restore normal joint function and minimize further degeneration, they often do not offer a long-term clinical solution. There is a clinical need to develop regenerative medicine approaches to permanently restore articular cartilage [11].

Both adult mesenchymal stem cells (MSCs) and induced pluripotent stem cells (iPSCs) are promising stem cell sources to achieve cartilage regeneration $[5,7,12-14]$. However, the use of adult MSCs still faces considerable challenges such as cell senescence and donor variability $[7,15]$. iPSCs may provide a suitable alternative in order to overcome the limitations of adult MSCs [7]. iPSCs possess unlimited self-renewal and pluripotency, similar to embryonic stem cells (ESCs), but lack the ethical concerns associated with the use of ESCs [1]. However, it remains to be determined whether differentiated iPSCs are able to form a bona fide cartilage [1]. Furthermore, more research is required to alleviate any concerns for tumorigenic effects before this technology can progress to preclinical and clinical usage $[16,17]$. Before any of these possible treatment options can be introduced into the clinic, they first have to be tested in suitable and translational animal models [9]. A wide variety of animal models is available to investigate cartilage regeneration ranging from small animal models, such as mice and rats, to larger animals such as canine, porcine, caprine, ovine, and equine models. Smaller animal models are costeffective and easy to house and offer a variety of genetically modified or immunocompromised strains. However, due to their small joint size and thin cartilage, their translational value is limited [9]. Larger animal models on the other hand more accurately approximate the human situation but are associated with greater logistical, financial, and ethical considerations [9].

In this review, recent in vitro data and preclinical studies justifying the use of MSCs and iPSCs in cartilage tissue engineering are summarized. Since preclinical studies require translational animal models, the advantages and disadvantages of small and large animal models will be discussed, while also focusing on suitable outcome measures for evaluating cartilage repair.

\section{In Vitro Evidence of Chondrogenic Differentiation of Stem Cells}

For stem cell-based cartilage regeneration, MSCs are of particular interest because, in comparison to chondrocytes, they have high availability and both easy isolation and expansion [18]. In addition, their in vitro chondrogenic differentiation has been proven [19]. More recently, in vitro studies on iPSCs indicated promising results for their use in cartilage repair $[20,21]$. However, a number of challenges have to be overcome and further optimization is still needed before both stem cell types can be used as a safe and effective therapeutic option for promoting cartilage repair [1, 14, 22-24].

2.1. Mesenchymal Stem Cells. Adult MSCs were first identified in bone marrow [25], but afterwards, other MSC niches have been discovered in both adult and fetal tissues, including adipose tissue [26], placenta [27], umbilical cord [28], dental pulp [29, 30], and peripheral blood [31], and in the synovial membrane [32]. As defined by the International Society for Cellular Therapy (ISCT), MSCs must be able to differentiate into chondrocytes under specific in vitro conditions [33]. In addition, MSCs possess additional properties making them a suitable cell source for cartilage regeneration. High cell numbers can be produced, and the immunomodulatory characteristics of MSCs allow for their allogeneic use [34].

Pellet and monolayer cultures are the two main culture systems that have been developed to study in vitro chondrogenic differentiation. The 3D pellet system is the most representative in vitro model for the condensation of mesenchymal cells that is observed during the initiation phase of chondrogenesis in the process of endochondral ossification $[35,36]$. Moreover, cocultures with chondrocytes in both 2D and 3D culture systems could push MSCs towards the chondrogenic lineage [37-39] and growth factors, such as insulin-like growth factor (IGF) [40] and members of the fibroblast growth factor (FGF) [41] and transforming growth factor-beta (TGF- $\beta$ ) [42-44] families, can be added to the differentiation medium to enhance chondrogenic differentiation. Additionally, the chondrogenic differentiation potential of MSCs and the production of ECM proteins can also be stimulated by combining MSCs and biomaterials in 3D scaffolds [45-52] or by manipulating the oxygen tension [53].

In vitro studies mainly focus on bone marrow-derived MSCs (BM-MSCs), followed by MSCs derived from adipose tissue and synovial membrane because of their easy isolation and close proximity to cartilage and joints, respectively [16]. A correlation between the chondrogenic potential of MSCs and their tissue source has been suggested. BM-MSCs showed a superior chondrogenic differentiation capacity compared to MSCs from other origins [54-56]. These differences might be explained by variations in gene expression and pathway activation [57]. Therefore, an adapted differentiation protocol could compensate for lower chondrogenic differentiation capacities $[57,58]$.

Despite their promising chondrogenic potential in vitro, several challenges are linked to the use of MSCs in cartilage regeneration. The most common issue is terminal differentiation towards hypertrophic cells [36]. Moreover, mineralization and vascularization have also been reported after transplantation $[35,59]$. In addition, cartilage tissue derived from in vitro differentiated MSCs resembles fibrocartilage with inferior mechanical properties and healing capacity [22]. Another limitation is the inter- and intradonor 
heterogeneity of MSCs which could influence chondrogenic differentiation potential of cells [60], depending on comorbidities, tissue source, and culture methods [24]. Furthermore, serial passaging, needed to obtain sufficient cell numbers for in vivo studies, has been reported to affect chondrogenic differentiation of BM-MSCs [61]. Finally, supplementation of the culture media with high and repeated doses of growth factors does increase the costs of stem cellbased therapy and might be associated with several side effects including synovial fibrosis, osteophyte induction, and other osteoarthritic-like symptoms [62, 63].

2.2. Induced Pluripotent Stem Cells. Part of the issues associated with MSCs can be circumvented by using iPSCs. iPSCs are an ideal patient-specific unlimited cell source for autologous tissue regeneration. Promising in vitro results have already been demonstrated in the cartilage engineering field for iPSCs generated from various cell types $[20,21,23,64$, 65]. Nevertheless, Guzzo et al. stressed the influence of cell type origin on their chondrogenic capacity, where superior properties could be assigned to iPSCs from chondrogenic origin [66], which may be due to the preservation of the epigenetic memory [67].

Analogous to MSCs, indirect cocultures of iPSCs with primary chondrocytes could directly induce the formation of chondrocytes [20]. Furthermore, iPSCs could be committed to the chondrogenic lineage in high-density pellet culture systems, enhanced by the addition of growth factors from the TGF- $\beta$ superfamily. Nevertheless, the resulting cartilage is a heterogeneous combination of hypertrophic, articular, and fibrocartilage [68]. This heterogeneity could be reduced by first differentiating iPSCs towards an intermediate cell population, such as MSCs $[68,69]$ or embryonic cell types $[23,65,70]$. An alternative approach to further enhance the chondrogenic potential is seeding iPSCs into scaffolds [71].

Although iPSCs express higher proliferation rates [72] and similar or superior chondrogenic differentiation potential $[14,64]$ compared to MSCs, other limitations remain associated with these stem cells. Patient-specific autologous iPSC generation and transplantation are very expensive. Allogeneic therapy would be more attractive, but immune rejection cannot be excluded [73]. Analogous to MSCs, it remains uncertain whether the regenerated cartilage induced by iPSCs preserves the mechanical and functional properties of native articular cartilage. Furthermore, also for iPSCs, the presence of hypertrophic signals under in vitro conditions, even though to a lesser extent than for MSCs, might indicate the formation of low-quality cartilage tissue by iPSCs $[14,23]$. Safety issue is the most important concern that hampers their general use [74]. The potential reactivation of pluripotency in iPSCs or iPSC-derived chondrocytes should be addressed [75]. Moreover, when using retrovirally transduced iPSCs, where the retroviral gene is integrated in the host, a higher risk for teratoma formation in cell transplants is reported [76]. Therefore, adequate phenotyping of (fully) chondrogenic committed iPSCs is needed before transplantation of cells in (pre)clinical use. Several approaches have been proposed to develop iPSCs with a lower risk for tumorigenicity $[69,75,77-79]$. Nakagawa et al. generated iPSCs without
Myc from mouse and human fibroblasts and reduced the tumorigenicity of cells [77]. Fusaki and colleagues induced transgene-free human pluripotent stem cells by means of a vector based on the Sendai virus, which does not integrate into the host [78]. Nejadnik et al. used the integration- and viralfree minicircle reprogramming technique to reduce the reactivation of pluripotency in the used human iPSC-derived chondrocytes [69]. Alternatively, transgene-free iPSCs can be used as generated by $\mathrm{Wu}$ and colleagues [80]. Additionally, iPSC-derived chondrocytes could be engineered to express a suicide gene in order to eliminate the cells, which was reported to be efficient in ESCs and BM-MSCs $[81,82]$.

\section{Mechanisms of Action of Stem Cell-Based Therapies for Cartilage Regeneration}

Stem cell-based therapies were initially developed as a cell replacement therapy due to the chondrogenic differentiation potential of stem cells $[14,23,52,83,84]$. Moreover, differentiated MSCs, ESCs, and iPSCs secrete PGs and collagen II [23, 85-88] which are essential components of cartilage tissue. However, it has been shown that upon intra-articular transplantation, MSCs induce cartilage replacement, but the principal source of repair tissue is derived from endogenous cells [89]. Therefore, it is postulated that the paracrine effect of the transplanted cells on the damaged host environment is mainly responsible for stimulating cartilage regeneration (Figure 1). MSCs that were exposed to tumor necrosis factor alpha (TNF- $\alpha$ ) and IL- $1 \beta$ were shown to upregulate the expression of several growth factors, anti-inflammatory mediators (vide infra), and anticatabolic factors ultimately leading to (stem) cell-mediated cartilage regeneration (reviewed in $[90,91])$. The main growth factors associated with cartilage regeneration that are secreted by MSCs belong to the TGF- $\beta$ superfamily [92]. Moreover, adipose tissue-derived mesenchymal stem cells (AT-MSCs) were demonstrated to diminish MMP-13 expression upon transplantation, potentially counteracting collagen degeneration in pathological cartilage [93]. In addition to the paracrine effect of soluble factors, extracellular vesicles (EVs), released by MSCs, have been shown to influence cartilage regeneration (Figure 1). Reports on stem cell EV-mediated cartilage repair are scarce. Studies showed that MSC-EVs promoted the formation of new cartilage and the deposition of collagen II and glycosaminoglycans (GAGs) [94]. Additionally, EVs from MSCs that overexpressed miR-140-5p stimulated chondrocyte migration and proliferation [95]. Moreover, it was recently reported that BM-MSCs secrete hyaluronan(HA-) coated EVs [96], which may allow MSC homing to cartilage defects in a receptor-mediated way via CD44. Although stem cell EVs have shown beneficial effects in cartilage repair, it should be noted that EVs may also have damaging effects in arthritis [13].

Furthermore, it has been demonstrated that MSCs possess immunomodulatory properties (Figure 1) [97]. Given the immune component underlying cartilage degeneration, modulating the immune response might contribute to reducing cartilage loss in diseases where an uncontrolled immune response is detrimental $[98,99]$. BM-MSCs, for example, 


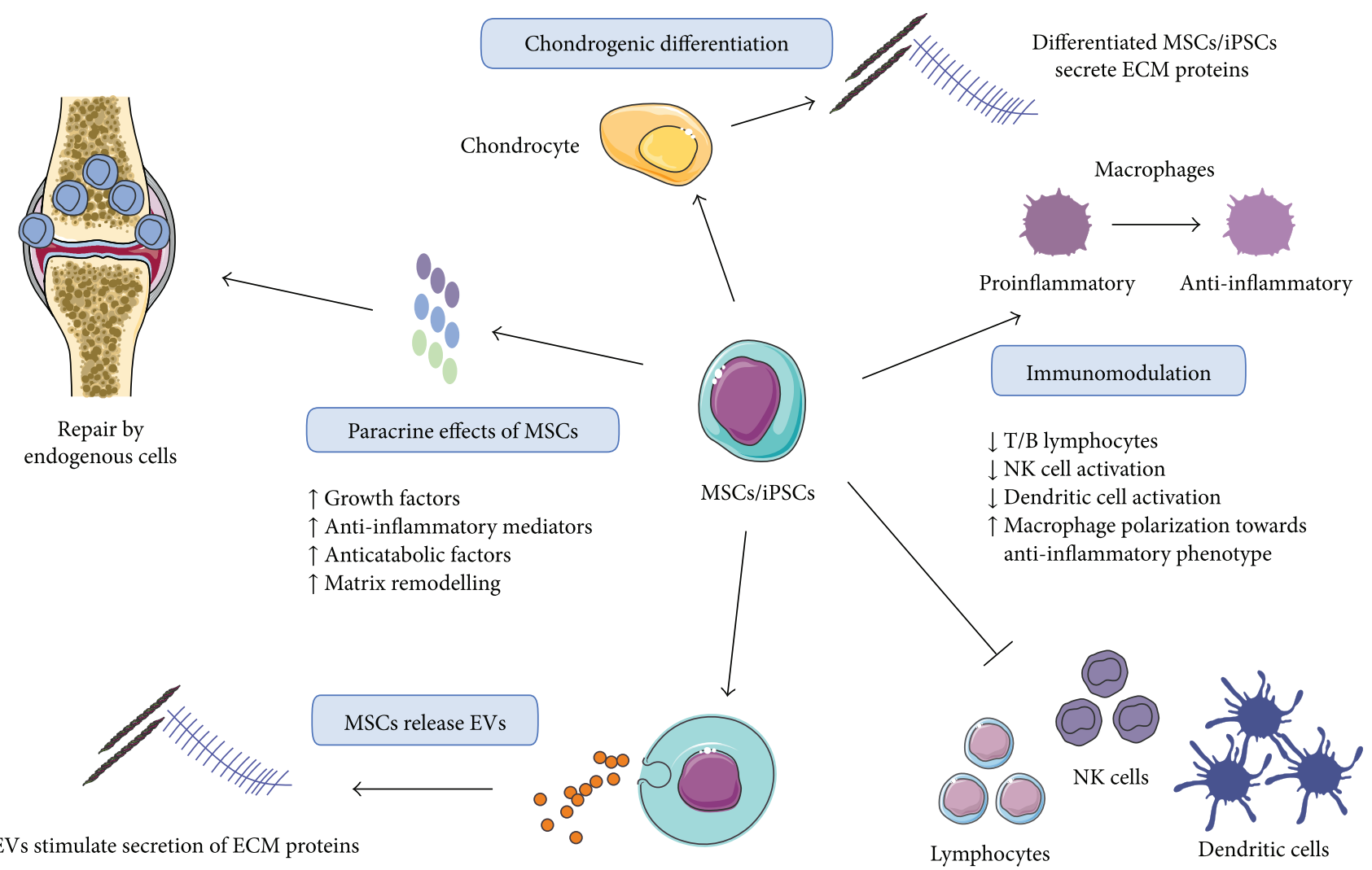

FIGURE 1: Mechanisms of action of stem cell-based therapies in cartilage regeneration. First, stem cells could be applied as cell replacement therapy because of their chondrogenic differentiation potential. Differentiated mesenchymal stem cells (MSCs) and induced pluripotent stem cells (iPSCs) secrete proteoglycans and collagen II. Secondly, it is suggested that the tissue is regenerated by endogenous cells under the influence of paracrine factors secreted by stem cells. Extracellular vesicles (EVs) contribute to stem cell-mediated cartilage regeneration by promoting the formation of new cartilage and the deposition of collagen II and GAGs. Finally, immunomodulatory effects are also observed. This image was created using Servier Medical Art.

have been shown to suppress T-cell proliferation $[100,101]$ and to induce T-cell apoptosis [102]. The resulting debris stimulated phagocytes to produce TGF- $\beta$ which increased the number of regulatory T cells [102]. Moreover, T-cell proliferation was inhibited by BM-MSCs that produced prostaglandin E2 (PGE2) and indoleamine 2,3-dioxygenase (IDO) $[103,104]$. These factors were also shown to inhibit NK cell activation [105]. Also, MSCs derived from the dental pulp possess immunomodulatory properties $[106,107]$. The proliferation, activation, maturation, and antigen presentation of dendritic cells were also inhibited by MSC subtypes [108-112], and macrophage/microglia polarization was shifted towards an anti-inflammatory phenotype after exposure to MSCs, their secretome, or EVs [110-115]. Additionally, MSCs were able to modulate the $\mathrm{B}$ cell response by paracrine actions $[116,117]$. Next to MSCs, iPSC- or ESCderived MSCs could also inhibit lymphocyte proliferation and function [118-121] and NK cell function [120].

\section{The Importance of a Translational Animal Model and Appropriate Outcome Measures}

While in vitro studies and models offer a substantial amount of information about the potential of stem cells for cartilage repair $[122,123]$, more in-depth knowledge about their behavior in vivo should be derived from immunocompetent animal models [124]. In orthopedic research, to move new technologies from bench to bedside, strict preclinical studies using translational animal models are required [125]. Preclinical studies evaluating the healing of cartilage defects have been performed using both small and large animal models including murine, lapine, porcine, caprine, ovine, canine, and equine models $[16,124]$. The following section will focus on the advantages and disadvantages of utilizing small and large animals for cartilage repair studies as well as some key factors in study design and the usage of validated outcome measures.

4.1. Choice of Animal Model: Small versus Large Animal Models. Articular cartilage defects have been created in small animals, such as mice [84], rats [126-129], and rabbits [130-132]. Smaller animal models are cost-effective and easy to house, and rodents are available in a variety of genetically modified strains with minimal biological variability $[9,124]$. However, the small joint size, the thin cartilage [133, 134], altered biomechanics $[135,136]$, and increased spontaneous intrinsic healing [137] hamper the study of the regenerative capacity of stem cells and these mechanisms of healing cannot be fully extrapolated to human cartilage repair $[9,124]$. Rodents have mainly been 
used to assess chondrogenesis of cell-based therapies by subcutaneous [138], intramuscular [139], and intraarticular [140] implantations of cells [9]. Of all small animals, the rabbit model is the most utilized model in cartilage regeneration studies because of the slightly larger knee joint size in comparison to rodents [16]. Despite their limited translational capacity, small animals can be very useful as a proof-of-principle study and to assess therapy safety before moving on to preclinical studies using larger animals $[9,125]$.

Large animal models play a more substantial role in translational research because of a larger joint size and thicker cartilage; however, their preclinical use is often hindered by high costs and difficulties in animal handling. A variety of large animal models have been used to investigate cartilage repair strategies, including horses [141-143], dogs [144], sheep [145-149], goats [150, 151] and (mini)pigs [152-155], each with their own strengths and limitations.

The knee anatomy [156-158], cartilage thickness $[133,159]$, biomechanical loading environment [124] and the subchondral bone properties [136] of the abovementioned species differ variously from the human condition $[124,160]$. An advantage of using the porcine model is the cartilage thickness of $1.5 \mathrm{~mm}-2 \mathrm{~mm}$, compared to human cartilage thickness of $2.4 \mathrm{~mm}-2.6 \mathrm{~mm}$ [152, 159]. Dogs, in contrast, have thinner cartilage $(0.95 \mathrm{~mm}-1.3 \mathrm{~mm})$ compared to human cartilage $[124,159]$. For the goat, cartilage thickness has been reported between $0.8 \mathrm{~mm}$ and $2 \mathrm{~mm}$, whereas cartilage thickness in sheep ranges from $0.4 \mathrm{~mm}$ to $1.7 \mathrm{~mm}[124,159]$. Of all animal models used in cartilage regeneration studies, the horse's cartilage thickness $(1.75 \mathrm{~mm}-2 \mathrm{~mm})$ provides the closest approximation to the human situation $[133,136,159,161]$.

In a comparative anatomical analysis, the goat stifle displayed strong anatomic similarities to the human knee except for a long trochlear groove with medial and lateral ridges and the intercondylar notch width $[124,156]$. According to Osterhoff et al., the ovine stifle is very similar to the human knee except for the femoral intercondylar notch width, the patellofemoral joint's biomechanics, and the proximal tibia's cortical bone stock [158]. More recently, Vandeweerd and colleagues described several anatomical features in the ovine stifle [157]. Although the goat and ovine stifles are very similar to the human knee, these few anatomical differences remain and should be taken under consideration when selecting them as a suitable animal model [156-158], which, for instance, can have an impact on the volume of the synovial cavity. In addition to similar knee anatomy, the caprine model has been reported to have similar stifle biomechanics compared to human knees $[124,162]$. While the horse model offers defect sizes comparable to human defect dimensions, the increased weight and the fact that the horse spends much of its time in standing position place defects under significant loading and this continuous loading cannot be diminished [159]. Nevertheless, this constant loading environment in the horse stifle joint could be argued to be beneficial for translational cartilage repair studies since the human knee provides a less challenging load environment [163].
Moreover, since numerous repair strategies rely on the subchondral repair mechanisms, subchondral bone properties must be considered when selecting the appropriate repair model [136]. According to Chevrier et al., the subchondral properties of the rabbit trochlea are similar to the human medial femoral condyle (MFC) [136]. The goat offers advantages in subchondral bone consistency, thickness, and trabecular structure, which are more similar to the human structure in comparison to either small animals, ovine models, or canine models $[9,124]$. A major disadvantage of the ovine and equine models is the dense and hard subchondral bone, while the caprine model has a softer subchondral bone $[9,159]$. In addition, subchondral bone cysts in sheep $[145,164]$ and goat [165] have been reported when the subchondral bone is involved in cartilage repair mechanisms [166].

Ultimately, when selecting the best repair model, comparable anatomy and joint function are not the only important aspects, but other factors need to be taken into consideration when performing translational preclinical studies (Table 1). A factor requiring major consideration is the choice of defect location [124]. Clinically, most defects are made on the femoral condyles or the trochlear groove [160]. However, defect position influences cartilage repair response as demonstrated in caprine and ovine models leading to contradictory results $[147,162]$. These differences in repair potential are due to differences in cartilage thickness, loading mechanics, and subchondral bone properties within the knee and between species [136, 147, 162]. In addition, defects may occur where higher loads are expected [167]. Ideally, these areas should be used when defects are induced. Therefore, it is important to identify the prevalence of naturally occurring defects in animal models and to assess where the lesion should be created based on the biomechanics of the joint of the animal [124, 167]. The ovine model is a well-documented model, where the most frequent naturally occurring cartilage defects in the ovine knee occur on the axial aspect of medial tibial condyle (MTC) and on the MFC [167]. Critical size chondral and osteochondral defects have been reported in rats, rabbits, dogs, (mini)pigs, sheeps, goats, and horses (as shown in $[125,159,168])$. Skeletal maturity and animal age also affect repair mechanisms of cartilage defects, especially when the subchondral bone is fractured for induction of repair [136, 137, 166, 169, 170]. Experimental models in animals that have reached skeletal and articular cartilage maturity are needed before the effect of any novel regenerative strategies on adult cartilage repair can be clinically evaluated. According to the International Cartilage Repair Society (ICRS) recommendations, selection of the age of an experimental animal should be based on cartilage maturity rather than on skeletal maturity (closure of the growth plate) [166]. Cartilage maturity can be defined as the time point where a cartilage defect is not spontaneously repaired and at the presence of a well-defined zonal architecture, an intact continuous layer of calcified cartilage, and minimal vascular penetration in the subchondral bone plate [166]. This would confirm that the articular cartilage has the adequate cellular, biomechanical, and biochemical properties. Therefore, in preclinical cartilage repair studies, animals at the age of 
TABLE 1: Key factors for the selection of a translational animal model for cartilage repair.

\begin{tabular}{|c|c|}
\hline Aspect & Remark/recommendation \\
\hline Anatomy and biomechanics & (i) Large difference in anatomy and biomechanics remains between animal models and humans \\
\hline Cartilage thickness & $\begin{array}{l}\text { (i) Large animals provide closer proximity to the human condition } \\
\text { (ii) Depends on topographic location in joint }\end{array}$ \\
\hline Subchondral bone properties & $\begin{array}{l}\text { (i) Effect on repair mechanisms } \\
\text { (ii) Depends on topographic location in joint }\end{array}$ \\
\hline $\begin{array}{l}\text { Defect dimensions and } \\
\text { location }\end{array}$ & $\begin{array}{l}\text { (i) Critical size chondral or osteochondral } \\
\text { (ii) Location of defect influences cartilage repair } \\
\text { (iii) Femoral condyles or trochlea } \\
\text { (iv) Defect should be made based on the biomechanics of the joint of the animal }\end{array}$ \\
\hline Age and gender & $\begin{array}{l}\text { (i) Age and gender may have effect on repair mechanism } \\
\text { (ii) Inclusion of skeletally mature animals with mature cartilage (human-near puberty) } \\
\text { (a) Rabbit-8 months } \\
\text { (b) Dog-24 months } \\
\text { (c) Pig-18 months } \\
\text { (d) Sheep-24 months } \\
\text { (e) Goat-24 months } \\
\text { (f) Horse-24 months } \\
\text { (iii) Gender effects must be taken into consideration } \\
\text { (iv) Use animals with short range of ages and with similar sex }\end{array}$ \\
\hline Study duration & $\begin{array}{l}\text { (i) Depends on type of study } \\
\text { (ii) Proof-of-principle ( }<6 \text { months) versus late-stage study ( } 6 \text { months- } 12 \text { months) }\end{array}$ \\
\hline $\begin{array}{l}\text { Surgical and practical } \\
\text { considerations }\end{array}$ & $\begin{array}{l}\text { (i) Unilateral versus bilateral repair models } \\
\text { (a) Unilateral models: evaluation of locomotion, range of motion and gait, better immobilization, and } \\
\text { no influence of contralateral technique } \\
\text { (b) Bilateral models: minimize interanimal variability } \\
\text { (ii) Postoperative management should be tolerated } \\
\text { (iii) Ethical permission for small animals and ruminants is easier to obtain } \\
\text { (iv) Surgical feasibility must be taken into account } \\
\text { (v) Financial costs to house and handle differ variously between animals } \\
\text { (vi) Availability of facilities, competent personnel, and equipment }\end{array}$ \\
\hline Validated outcome measures & $\begin{array}{l}\text { (i) At baseline, in vivo and post mortem } \\
\text { (ii) Clinical response and kinematics } \\
\text { (iii) Biological fluid collection } \\
\text { (iv) Noninvasive compositional imaging MRI } \\
\text { (v) Ex vivo high resolution magnetic resonance imaging (MRI) or microcomputed tomography }(\mu \mathrm{CT}) \\
\text { (vi) Tracking and monitoring } \\
\text { (vii) Macroscopic/arthroscopic scoring } \\
\text { (viii) Histological and histomorphometric scoring } \\
\text { (ix) Mechanical testing } \\
\text { (x) Biomolecular and biochemical testing }\end{array}$ \\
\hline
\end{tabular}

cartilage maturity, defined based on the aforementioned conditions, should be used (Table 1) [166].

While the choice of animal age, critical defect dimensions, and location in preclinical studies is often justified, gender selection is frequently overlooked. Regenerative strategies to address cartilage lesions and osteoarthritis have not sufficiently considered possible gender differences [171]. Therefore, potential gender effects must be taken more into consideration during analysis. Epidemiological studies demonstrated the presence of sex differences in osteoarthritis prevalence and incidence with females being at a higher risk to develop more severe knee osteoarthritis after reaching menopausal age [171]. Several researchers examined the role of sex hormones in osteoarthritis, including in ovine and murine models [167, 172-174]. Ma and colleagues showed that sex hormones, both testosterone and oestrogen, have a crucial influence on the advancement of osteoarthritis in mice. Testosterone aggravated the disease in male mice evidenced by the fact that orchiectomized mice showed a less severe osteoarthritis than intact males. Healthy female mice showed less severe osteoarthritis than ovariectomized females, demonstrating the protective role of female hormones [174]. In a biomechanical study in sheep, ovariectomy in females induced a detrimental effect on the intrinsic properties of the articular cartilage in the knee [172]. In human subjects, differences in knee joint volume and articular surface areas between men and women have been described [175]. Moreover, gender differences in cartilage composition and gait mechanics in young healthy, middle-aged healthy, and osteoarthritis cohorts are reported [176]. These 
differences might influence functional outcome after repair [177]. Thus, effective and well-designed regenerative preclinical studies are required and should lead to a better understanding of gender-specific differences in the mechanisms involved in cartilage re- and degeneration. Since osteoarthritis and cartilage biology are reported to be sexdependent, the inclusion of female animals is essential for preclinical cartilage repair studies. If both sexes are included, an equal number of males and females per study group with short ranges of ages should be used. Moreover, results should be reported for both genders and per study group [171]. In addition, for large animals, it is more difficult to manage male animals, since sexual behaviour and mounting may increase loads on high limbs.

Obviously, the recommended study duration for evaluating cartilage repair in preclinical animal models is different for proof-of-concept or pilot studies ( $<6$ months) versus late-stage preclinical studies in large animal models $(>6$ months) $[124,125,166]$. However, for late-stage preclinical studies, caution must be exercised when the study ends within a year or when no interval follow-up investigations are implemented since the repaired tissue can vary at earlier phases of healing and the sustainability of the repaired tissue is time-dependent $[148,153,166]$. Follow-up methods of noninvasive imaging are necessary $[178,179]$. Ovine models allow for imaging techniques such as magnetic resonance imaging (MRI) [166, 180], while the equine model is much more difficult, or impossible, due to the size of animal versus size and costs of high-field MRI. Furthermore, the nature of the regenerative strategy, such as the use of autologous or allogeneic cell therapy, also needs to be considered. Other key issues in cartilage repair models are the choice of bilateral versus unilateral surgery and acute versus chronic defects $[148,166]$. Bilateral repair models are suitable to minimize interanimal variability and to increase the number of treated limbs but are only useful if the treatments are not reciprocally influencing the opposite limbs [181]. Unilateral models, in contrast, ensure that the treatment is not influenced by the contralateral technique. In addition, these models allow easier joint immobilization and are exposed to less initial weight bearing on the operated limb. More importantly, unilateral models permit better evaluation of locomotion, range of motion, and gait [166].

The choice of animal model is also influenced by practical aspects such as ethical considerations, costs, and availability of housing accommodations, materials, and competent personnel [160]. Nowadays, it is increasingly difficult to obtain ethical permission for the usage of dogs and horses, while working with reformed sheep or goats is much easier to justify. Surgical limitations, such as the ability of the animal to tolerate anaesthesia and postsurgical recovery protocols or the possibility of second-look access, could influence the choice of a specific animal model [141, 142, 166, 182]. The ovine model, for instance, is particularly easy to handle, cost-effective, and easy to anaesthetize.

4.2. Follow-Up and Outcome Measures. Preclinical animal studies analyzing the capacity of new technologies in cartilage regeneration frequently suffer from a lack of noninvasive follow-up and outcome measures and are therefore often forced to use endpoint outcome measures such as histology and destructive mechanical testing (Table 1). Additionally, there is an increasing need for standardized technologies with a diagnostic significance over the whole defect and adjacent tissues, while incorporating reflections of costs, care, and ethics and mimicking the clinical investigations in human clinical trials [166, 178].

For longitudinal in vivo studies, it is advised to assess the animal at baseline and at different time points. Depending on the animal, healthy joint status at the start of the study should be evaluated via diagnostic imaging modalities since variability in cartilage thickness, bone structure, and the prevalence of naturally occurring cartilage defects and other lesions associated with osteoarthritis can occur among species [167, 183-185]. More specifically, spontaneously occurring cartilage lesions have been described in canine, equine, and aging ovine models $[9,166,167]$. Canine and equine models should be screened for naturally occurring osteoarthritis, since they can have lesions associated with osteoarthritis or osteochondritis dissecans $[9,166]$. Noninvasive imaging of articular cartilage defects can be performed by magnetic resonance imaging (MRI) [186-188] or computed tomography arthrography (CTA) $[185,189,190]$. CTA has been shown to be more accurate than MRI to detect cartilage defects in humans [185, 191]. Recently, Hontoir et al. described CTA to be an accurate imaging method for detecting articular cartilage defects in the ovine stifle [185]. Additionally, the same authors compared the sensitivity and specificity of 3-Tesla (3-T) MRI and CTA to identify structural cartilage defects in the equine metacarpo/metatarsophalangeal. Hontoir and colleagues showed that CTA is superior to MRI due to its shorter acquisition time, enhanced correlation to macroscopic assessment, and its specificity and sensitivity in identifying articular cartilage defects; nonetheless, MRI has the advantage to assess soft tissues and subchondral bone [189].

For the visualization of cartilage, diagnostic imaging techniques such as ultrasound, computed tomography (CT), and MRI can be used $[125,178]$. More recently, novel quantitative MRI and CT techniques are being adopted as outcome measures after cartilage repair $[178,188,190]$. Compositional imaging MRI is being progressively applied to assess the biochemical composition of cartilage for the longitudinal follow-up of cartilage repair studies [179]. More specifically, T2 mapping combined with delayed gadoliniumenhanced MRI of cartilage (dGEMRIC) seems to be a good compositional imaging modality to monitor cartilage repair and to discriminate between a collagen network with zonal organization and healthy cartilage [179, 192]. Combining multiple imaging techniques may yield a better understanding of both the collagen and PG content of the repaired defect [193]. T2 mapping provides information about the interaction of water molecules and the collagen network, while dGEMRIC evaluates GAG concentration within the cartilage [194]. In human patients, Kurkijarvi et al. demonstrated that combining datasets from dGEMRIC and T2 relaxation time mapping provides additional information on cartilage repair [192]. Recently, T2 mapping and dGEMRIC were used for assessing cartilage repair after allograft chondrocyte 
implantation in a rabbit model, where dGEMRIC data showed a high correlation with histological and biochemical data [194]. In goat models, T2 mapping and dGEMRIC have also been used as outcome measures in a study evaluating cartilage repair after microfracture in an osteochondral defect of both the medial and lateral femoral condyles [195]. Alternatively, T $1 \rho$ has been used as a complementary imaging tool to T2 mapping which allows for the examination of PGs and the collagen organization [179]. However, one of the major issues of using $\mathrm{T} 1 \rho$ is reaching an adequate resolution with an acceptable acquisition time [179]. More recently, van Tiel and colleagues showed that dGEMRIC is more robust in accurately measuring cartilage GAGs in vivo in patients compared to T1 $\rho$ mapping [196].

Although substantial progress has been made in real-time in vivo cartilage imaging, spatiotemporal tracking of stem cells in vivo using MRI, bioluminescence imaging (BLI), fluorescence imaging (FLI), or nuclear imaging methods should be the focus when developing novel imaging techniques [178]. Superparamagnetic iron oxide (SPIO) particles are used for cartilage tissue engineering to monitor transplanted cells $[197,198]$. However, SPIO particles are associated with several drawbacks such as the inability to distinguish viable cells from dead cells and from cells engulfed by phagocytes [199]. One of the possibilities to minimize particle transfer to other cells is the use of reporter genes. BLI compatible reporter genes such as red/green luciferases have already been used for cartilage tissue engineering to track transplanted cells [200]. In addition, by labeling cells with an additional chondrogenic reporter gene, cell differentiation can be monitored by means of dual bioluminescence labeling [201]. While this optical imaging method offers a sensitive technique to track stem cells, its use in larger animal models is limited because of a loss of signal intensity from deeper tissues due to scattering [202].

At baseline and at longitudinal intervals, clinically relevant examinations of cartilage repair and functional improvement should be carried out. These should be performed by a veterinary surgeon familiar with observing clinical signs and locomotion by assessment of changes in joint palpation, quantitative monitoring of pain, and changes in joint function or locomotion by gait analysis [125, 166, 203-206]. In rats, several scoring systems have been published to measure lameness, stride length and limb rotation, dynamic force application, and hind limb motion [206]. Moreover, for large animal models, kinematic marker analysis, ground reaction force measurements, and observational gait assessment have been progressively used in osteoarthritis-related gait alterations in canine, ovine, and equine models [206]. Several scaling systems have been documented in the literature, such as the American Association of Equine Practitioners (AAEP) lameness scale in the horse ranging from zero to five [207]. In ovine models, a numeric ranking scale can be used to determine comfort, movement, and flock behaviour [204]. A more detailed lameness scoring system has been published by Kaler et al. ranging from "normal" (0) to "unable to stand or move" (6) [203]. Overall, clinical assessment and gait monitoring are indispensable in order to increase the translational value of preclinical animal studies to human clinical trials and to the clinic.

Biomarkers represent an additional tool to evaluate normal and pathological processes or to evaluate the interventional repair strategies [208, 209]. These biomarkers may be identified and quantified via enzyme-linked immunosorbent assays (ELISA) or other protein assays in synovial fluid or other biological fluids such as in the blood and urine [208, 209]. Synovial and other biological fluid collections should be performed at baseline and multiple time points [166], since synovial fluid biomarkers have the capacity to reflect the articular environment before treatment and could possibly inform on postoperative outcomes [208]. In small animal models, however, it can be difficult to obtain sufficient amounts of biological fluid at multiple time points necessary for biomarker analysis [210]. To solve this, the use of paper or alginate to obtain small amounts of synovial fluid has been described to be successful and effective [211]. Because of the relatively larger joint size in large animal models, a collection of synovial fluid and serum biomarkers can be more easily performed [161]. Nevertheless, a major difficulty to perform repeated collections is the increased inflammation in the joint due to iatrogenic damage. Biomarkers of particular interest are markers for cartilage or synovium metabolism or markers involved in pathological pathways, such as inflammation [209]. Recently, biological (synovial) fluid markers in osteoarthritis were thoroughly reviewed by Nguyen and colleagues [209]. Besides analyte quantifications to assess changes in inflammation and cartilage turnover, volume and physical characteristics of the synovial fluid, such as viscosity, could also be used as an outcome measure in preclinical studies [166].

At the end of in vivo studies, cadaver tissue can undergo ex vivo high-resolution MRI $[212,213]$ and $\mu \mathrm{CT}$ [214] to evaluate structural improvements. Hereafter, macroscopic/ arthroscopic scoring, histological and histomorphometric scoring methods, quantification of collagen and GAG expression by immunohistochemistry, collagen organization by polarized light microscopy and subchondral bone, and adjacent tissue integration are all outcome methods that should ideally be performed [214-218].

Nowadays, many histological scoring systems are available, contributing to the confusion on the use of an appropriate scoring method for a specific research question and study settings [219]. Moreover, it is unclear which scoring systems are validated and how study results can be compared between studies using different scoring methods [219]. The variety of histological scoring systems for the analysis of normal or osteoarthritic in vivo repaired or in vitro tissueengineered cartilage was thoroughly reviewed by Rutgers et al. [219]. Normal cartilage can be distinguished from osteoarthritic cartilage via the Histological-Histochemical Grading System (HHGS) or HHGS-related systems and the Osteoarthritis Research Society International (OARSI) scoring method [219]. Of the various scoring systems available for the analysis of in vivo repaired cartilage, the ICRS II score seems most suitable in humans. In preclinical cartilage repair studies, the validated Pineda score or O'Driscoll score is advisable [219]. Other histological scoring systems 
for preclinical cartilage repair are widely used. In addition to the Pineda score, the Wakitani score is an elementary scoring system, reflecting not more than five parameters [220]. The Pineda score assesses four histological parameters: cell morphology, matrix staining, lesion filling, and osteochondral junction [220]. The O'Driscoll score is a more complex histological scoring method which also assesses surface regularity, structural integrity, cellularity, chondrocyte clustering, adjacent bonding, and adjacent cartilage degeneration. In addition to the O'Driscoll score, also the Fortier and Sellers scores are more comprehensive scoring systems [220]. Orth et al. showed that both elementary and comprehensive histological scoring systems are appropriate to quantify articular cartilage repair [220]. However, complex scoring systems provide more descriptive data about the character of the repair tissue [220]. The use of validated scores, such as the Pineda score or the O'Driscoll score, may significantly increase comparability of information and should thus stimulate consistency between studies. Importantly, histological and biochemical evaluations are complementary tools to assess experimental articular cartilage repair in vivo [219]. A key goal of regenerating mature cartilage tissue is to regenerate a tissue with biochemical/biomolecular and mechanical properties resembling those of native cartilage tissue. Small biopsies for biochemistry (water content, GAGs/PG content, and collagen content) and/or biomechanical testing should ideally be gathered before fixation of the repaired tissue for histology [217]. In addition to typical end-point destructive measures to assess mechanical properties, indentation testing provides a nondestructive compressive technique for in situ mechanical evaluation [178, 221]. Large animal models allow the harvest of a large amount of repaired tissue in order to have parallel histological, biochemical, and biomechanical analyses of the repaired area postmortem [166, 222].

Finally, the combined utilization of in vivo clinical tests and assessment of locomotion, in vivo noninvasive imaging methods, and postmortem evaluation of tissue structure with validated scoring systems, biochemical composition, and mechanical properties will deliver a robust outcome analysis in order to improve the translational value of animal models in cartilage repair.

\section{In Vivo Evidence of Stem Cells in Cartilage Regeneration}

Within the field of cartilage regeneration, numerous preclinical studies have been published demonstrating the favorable effects of cell-based approaches on the repair of cartilage defects. Although the cartilage contains an inherent progenitor cell population [223-225], to our knowledge, robust scientific reports describing their in vivo regenerative potential in particular defects are currently lacking. Given their aforementioned in vitro properties, certain pluripotent and multipotent stem cell populations are considered to be credible candidates for stem cell-based repair and regeneration of cartilage tissue. iPSCs, for example, have been shown to successfully repair cartilage defects in a variety of rat models, following predifferentiation towards a chondrogenic lineage $[14,69,226]$. However, due to their pluripotent nature, the use of these stem cells still bears the risk of tumorigenesis [1]. Saito and coworkers, for instance, reported the formation of an immature teratoma in one animal, following a prolonged transplantation period of predifferentiated iPSCs in the knee joints of immunocompromised mice [74].

With regard to multipotent stem cell populations, one of the most frequently applied stem cell sources in the repair and regeneration of articular cartilage defects are MSCs. BM-MSCs in particular have been used in a wide variety of small and large animal models [16, 227]. Zhang et al., for example, recently demonstrated the regeneration of meniscal tissue after transplantation of BM-MSC-seeded poly( $\varepsilon$-caprolactone) (PCL) scaffolds in rabbits [228]. Formation of hyaline-like cartilage tissue was also observed after the treatment of a canine osteochondral defect with autologous BM-MSCs [144]. Sridharan and coworkers reported the successful repair of a rat trochlear knee defect after transplantation of high density BM-MSC/fibrin aggregates [229]. Similar results were found by Itokazu et al., indicating osteochondral repair in nude rats after transplantation of human BM-MSC cell sheets [230].

Although BM-MSCs are reported to have a predominantly positive effect on cartilage repair and regeneration, their invasive collection as well as the limited yield of stem cells during this procedure encourages the search for alternative tissue sources of MSCs [231, 232]. Substantial amounts of AT-MSCs, for example, can be relatively easy to be obtained through liposuction, and their intrinsic behavior does not seem to be affected by donor-related characteristics, such as age [231, 233]. Recent work of Mehrabani and coworkers demonstrated the successful formation of hyaline cartilage tissue after intra-articular injection of AT-MSCs in the knee joints of rabbits [234]. Implantation of scaffoldfree spheroids of AT-MSCs into an osteochondral defect in two adult (mini)pigs led to the regeneration of the original cartilage tissue [235]. While hypoxic preconditioning of AT-MSCs had no effect on their in vivo chondrogenic potential [236], pretreatment of these stem cells with activated platelet-rich plasma substantially improved articular healing after transplantation in immunocompromised mice [237]. However, in comparison to BM-MSCs, AT-MSCs exhibit a significantly lower osteogenic and chondrogenic differentiation potential both in vitro and in vivo [55, 238-240].

Synovium-derived MSCs, on the other hand, not only display a higher proliferation potential in comparison to other sources of MSCs but also show a more pronounced production of cartilage-specific ECM when transplanted into an osteochondral defect in rabbits [238, 241, 242]. Similar findings were reported by Nakamura and coworkers, indicating the successful formation of cartilage tissue after intraarticular injection of allogeneic synovium-derived MSCs in the knee joints of pigs [243].

With regard to the mechanisms underlying the favorable effects of MSCs in cartilage repair, it remains unclear whether chondrogenic differentiation is a necessary prerequisite for cartilage tissue engineering as an increasing amount of evidence suggests that both the secretion of paracrine factors and the subsequent attraction of resident cells can also mediate tissue regeneration $[7,244]$. In order to promote 
these complex interactions, MSCs may be combined with chondrocytes in coculture systems, supported by exogenous growth factors and/or biomaterials to recreate the most optimal microenvironment for cartilage repair and regeneration [245]. Sabatino et al., for example, reported the successful production of cartilage grafts in a proof-of-principle mouse model. After subcutaneous transplantation of (precultured) collagen sponges containing BM-MSCs and articular chondrocytes, an increased GAG and collagen type II content was observed [246]. Similar results were found by Cai et al., indicating the formation of cartilage-specific ECM after subcutaneous transplantation of AT-MSCs and auricular chondrocytes supported by Pluronic F-127 [247]. In addition to subcutaneous transplantation, cocultures have also been directly applied in cartilage defects. Successful regeneration of meniscus tissue was demonstrated after transplantation of a polyvinyl alcohol/chitosan scaffold containing an AT-MSC/chondrocyte coculture in New Zealand rabbits suffering from a unilateral, medial meniscectomy. However, no significant differences were observed between the coculture scaffolds and the scaffolds merely containing articular chondrocytes [248].

In terms of delivery methods, numerous researchers used a scaffold-free intra-articular injection of stem cells. Nam and colleagues conducted a pilot study to test the effects of an intra-articular injection of autologous mesenchymal stromal cells on the repair outcomes of bone marrow stimulation (BMS) surgery in a caprine model. Results showed that the intra-articular injection of BM-MSCs following BMS intervention induced better cartilage repair outcomes [150]. In another study, MSCs were injected with hyaluronic acid (HA) and this resulted in good defect coverage at 12 weeks postinjection in a pig model [249]. The major advantage of an intra-articular injection of stem cells is the simplicity of the administration, but it would only be useful in early stages of cartilage injury. Additionally, intra-articular injection can lead to cell dispersion and an insufficient amount of cells reaching the defect required for repair [227]. One way to solve this is by using a local adherent technique for transplanting MSCs to the cartilage defect. Koga et al. showed in a pig model that placing an MSC suspension on the cartilage lesion for 10 minutes resulted in adherence of more than $60 \%$ of cells to the defect and induced cartilage regeneration [250]. Similarly, Nakamura and colleagues recently showed the same adherent technique with synovial MSCs in a pig model [243]. Unfortunately, by using these techniques, the transplanted cells lack an ECM, which makes it challenging to exploit the function of cells since the $3 \mathrm{D}$ environment is reported to be crucial in the processes of cell proliferation and differentiation [251]. To address this, a novel scaffoldfree 3D tissue-engineered construct (TEC) has recently been developed, composed of native ECM, synthesized by MSCs [251]. In addition, MSCs seeded in acellular cartilage matrices/sheets also showed successful cartilage repair $[252,253]$.

Scaffolds are preferably biocompatible or biodegradable and can be implemented via a minimally invasive surgical procedure. Furthermore, they should provide rigid mechanical properties and offer some additional advantages such as adequate nutrient transport and adhesion to the defect
[254]. Stem cells have been combined with a wide variety of natural and synthetic biomaterials to support and promote cartilage repair and regeneration [16, 231, 255-257]. This combinatorial approach has led to several successful in vivo applications of cell-seeded biomaterials for cartilage repair $[14,51,52]$. Of the various scaffold materials, the most commonly explored are hydrogels, which are cross-linked water-swollen systems [254]. Hydrogels gained a lot of interest because of their ability to homogeneously contain cells in a $3 \mathrm{D}$ environment and the minimal invasive injection procedure $[254,258,259]$. Natural hydrogels based on polysaccharides, such as chitosan, HA, alginate, and agarose, have been reported to support cartilage regeneration [254]. Recently, it was shown that MSCs isolated from the dental pulp cultured in an alginate scaffold successfully regenerated articular cartilage [260]. HA-based hydrogels are one of the most extensively used hydrogels in cartilage repair [254] and have been reported to improve cartilage specific-matrix deposition of MSCs [254, 259, 261]. In a direct comparative study in rats between several hydrogels such as alginate, pluronic, HA, and chitosan with human umbilical cord blood derived mesenchymal stem cells (hUCB-MSCs), the combination of hUCB-MSCs-HA resulted in superior cartilage repair on a macroscopic and histological level [262]. Similarly, combining hUCB-MSCs with a HA hydrogel promoted cartilage regeneration in an osteochondral defect minipig model [155]. With regard to natural biomaterials and hydrogels based on proteins such as collagen, gelatin, fibroin, and fibrin, Wilke et al. described an early chondrogenic response after intra-articular injection of a fibrin gel containing BMMSCs in horses [142]. Fibrin is a commonly used natural protein with chondrogenic-inducing properties [254, 259]. However, one of the major disadvantages of using fibrin gels is the fast degradation [263], resulting in less beneficial results in vivo [264]. More recently, platelet-rich fibrin (PRF) has gained more interest to provide a $3 \mathrm{D}$ environment for stem cells, consisting a strong fibrin network and supportive platelets. PRF has the ability to support the proliferation of MSCs and favors cytokine enmeshment and cellular migration [144]. Kazemi and colleagues showed that the use of BM-MSCs seeded on PRF could be a novel method for articular cartilage regeneration, where the PRF creates a suitable environment for stem cell proliferation and differentiation by secreting growth factors [144]. Alternatively, collagen is abundant in native articular cartilage and is therefore widely used in preclinical animal studies as a stem cell carrier [254]. The application of collagen combined with BM-MSCs led to fully repaired cartilage tissue in a porcine model [265]. However, the softness of collagen gels is one of the major concerns for in vivo cartilage repair [254]. Recently, a natural type II collagen hydrogel, fibrin sealant, and adipose-derived stem cells have been recommended as a positive combination for articular cartilage repair in rabbits [266]. In addition, transplantation of synovium-derived MSCs in a combination of collagen type I/HA/fibrinogen composite gel induced the formation of hyaline cartilage tissue in a lapine osteochondral defect model [242]. One of the major limitations of natural hydrogels is the low mechanical strength [259], which needs further modifications or combinations with 
other natural or synthetic polymers (composite scaffold). A number of advantages were also reported for synthetic polymers, such as a controlled degradation and good mechanophysical properties [267]. Poly-(lactic-(co-glycolic)) acid (PL(G)A), for example, is one of the most widely applied synthetic scaffold materials in stem cell-based cartilage tissue engineering [16]. Recent work of Yin et al. showed the regeneration of articular cartilage after transplantation of a TGF$\beta 1$-immobilized PLGA scaffold seeded with AT-MSCs into a full-thickness cartilage defect in New Zealand white rabbits [268]. Similar findings of successful cartilage engineering were reported earlier for BM-MSCs, indicating the successful formation of hyaline cartilage tissue by connective tissue growth factor- (CTGF-) modified stem cells contained within a sodium hydroxide-treated PLGA scaffold [269]. Caminal et al., however, only demonstrated a transient improvement caused by BM-MSC-seeded PLGA scaffolds in sheep with a critical size chondral defect [270]. Recently, hiPSCs-MSCs were seeded onto a PLGA scaffold and transplanted into a cartilage defect in a rabbit model. Results showed that the hiPSCs-MSCs-PLGA scaffold experimental group had the potential to repair cartilage defects in vivo [132]. One of the major disadvantages of using such synthetic polymers is the possibility to elicit an immune response [267]. Moreover, synthetic biomaterials lack biocompatibility and biological activity [259]. As previously mentioned, it is better to combine a synthetic polymer with a natural polymer to improve biological activity [259]. Many other scaffold materials have been tested in an attempt to improve cartilage repair by using MSCs. A wide overview of most used scaffolds can be found in the review article published by Goldberg and colleagues [16].

In order to make human stem cells applicable to human clinical translation, more in-depth knowledge about their in vivo behaviour should be derived from larger immunocompetent animals. Several researchers used human MSC transplantation in smaller nonimmunosuppressed animals and reported no graft rejection [271, 272]. Transplantation studies in larger animal models such as immunocompetent dog and swine reported similar results and even point out immunosuppressive capacities which are related to the MSC transplantation [273, 274]. Dayan and colleagues demonstrated that transplantation of human MSCs in ovine immunocompetent animal models showed clinical safety and efficacy suggesting that immunocompetent sheep can serve as a suitable preclinical large animal model for testing human stem cells [275]. In the unfortunate case of detecting an immunogenic response following human stem cell transplantation into the animal model, generally known immunosuppressive drugs can be administered at the time of transplantation. Alternatively, autologous transplantation of stem cells can be considered. However, one of the disadvantages of using autologous stem cells isolated from larger animals is the lack of well-characterized species-specific stem cells and protocols for their culturing and differentiation [276]. For autologous iPSCs in preclinical research in animal models, it appears that iPSCs in farm animals have not yet received the deserved attention [277]. Ogorevc et al. described only 32 studies addressing the development of
iPSCs in pig, cattle, horse, sheep, goat, and rabbit [277]. In addition, large animal commercial products, such as antibodies, reagents, and microarrays, are not widely available [276]. Nevertheless, beyond any doubt, for translational research in cell therapy, testing human stem cells in preclinical animal models which are immunocompetent should gain more attention.

\section{Conclusion}

Despite the multiple promising mechanisms of action of stem cell-based therapies for cartilage repair, supported by advances in bioengineering and biomaterials to exploit the full potential of stem cells, it is not yet possible to achieve engineered cartilage possessing identical properties as native cartilage $[17,278]$. Several concerns have to be addressed when considering these therapies for largescale human translation.

Before moving to the clinic with a universally applicable therapy, issues involving the heterogeneity of MSC sources as well as the heterogeneity within MSC populations, isolation methods, and differentiation protocols should be addressed [24]. Other factors such as aging [279], serial passaging [61], and the presence of comorbidities in the donor [60] can restrict the chondrogenic differentiation potential of MSCs. Furthermore, MSCs mainly produce collagen type I, while the main collagen subtype in the cartilage is collagen II. This needs to be taken into account to avoid the production of fibrocartilage or ossified hypertrophic cartilage [280]. Biomaterials can be used in combination with stem cells in order to support and promote cartilage repair and regeneration $[16,278]$. In the future, biomaterials can offer enhanced control of cell fate, enable sustained and localized release of paracrine factors, and facilitate remodeling of newly formed tissue [7].

Despite conflicting preclinical results, the use of allogeneic MSCs is gaining support as it avoids donor site morbidity and allows for single-stage procedures, thereby reducing the financial burden and increasing the simplicity of cellbased therapies [16]. Since different stem cell sources show inherent differences in their differentiation potential, secretome, and ECM profile, various MSC sources should be compared to select the most promising one for allogeneic therapies [7]. However, applying therapies involving allogeneic MSCs on a large scale requires cell banking possibilities and long-term safety and efficacy studies in order to assess possible immune rejection.

iPSCs have been explored as a possible alternative to MSCs due to their superior self-renewal capacity [1], proliferation rate [72], and chondrogenic differentiation potential $[14,64]$. However, the most important obstacle in the use of iPSCs is the risk for teratoma formation after transplantation [1]. Therefore, before this technology can progress to clinical translation, research into the control of cell phenotype and cell fate is required in order to alleviate the concerns for tumorigenesis [16].

Under ideal circumstances, novel therapies would reach the market after in vitro data were used to inform preclinical studies, which in turn led to human clinical trials [16]. 
Researchers should be aware that every animal model is associated with its advantages and disadvantages and the choice of the model should match the research hypothesis and is important to ensure the translation to the clinic $[9,124]$. Furthermore, the current lack of standardized protocols (i.e., cell delivery route and number of transplanted cells) as well as the wide variety of different outcome measures used to evaluate preclinical studies makes it difficult to draw definite conclusions regarding the potential use of stem cell-based approaches in cartilage tissue engineering through direct comparison of studies. Furthermore, gender differences in most animal studies have not been adequately investigated and should gain more attention. Moreover, the same applies for in vitro studies, where researchers, using primary cells or cell lines, often do not compare results between sexes. For cell lines, the gender of the cell line provided is frequently not mentioned, leading to conclusions which cannot be drawn for the whole population [171].

Despite these hurdles, at least 19 clinical trials have been registered using stem cell-based therapies for cartilage repair procedures [278]. Unfortunately, the quality of the existing clinical data is rather limited, but more recently registered clinical trials are showing improvement in the study design and methodology. This might in part be explained by the methodical recommendations developed by the ICRS [281]. This consensus statement includes guidelines for the statistical study design, patient recruitment, and considerations for appropriate control groups in order to help clinicians achieve high-quality data [281].

\section{Conflicts of Interest}

The authors declare that there is no conflict of interest regarding the publication of this article.

\section{Authors' Contributions}

Jean-Michel Vandeweerd and Ivo Lambrichts contributed equally to this work.

\section{Acknowledgments}

The study was performed within the framework of the cooperation between the University of Namur and Hasselt University. Melissa Lo Monaco is funded by "Bijzonder Onderzoeksfonds" and "Fonds Spécial de Recherche" (BOF16DOCNA02-FSR-confin UHasselt-UNamur). Jessica Ratajczak, Pascal Gervois, Petra Hilkens, and Annelies Bronckaers are funded by "Fonds Wetenschappelijk Onderzoek." Greet Merckx is funded by "Bijzonder Onderzoeksfonds."

\section{References}

[1] N. Tsumaki, M. Okada, and A. Yamashita, "iPS cell technologies and cartilage regeneration,” Bone, vol. 70, pp. 48-54, 2015.

[2] A. J. Sophia Fox, A. Bedi, and S. A. Rodeo, "The basic science of articular cartilage: structure, composition, and function," Sports Health: A Multidisciplinary Approach, vol. 1, no. 6, pp. 461-468, 2009.
[3] J. W. Alford and B. J. Cole, "Cartilage restoration, part 1: basic science, historical perspective, patient evaluation, and treatment options," The American Journal of Sports Medicine, vol. 33, no. 2, pp. 295-306, 2005.

[4] J. M. Cottom and J. M. Maker, "Cartilage allograft techniques and materials," Clinics in Podiatric Medicine and Surgery, vol. 32, no. 1, pp. 93-98, 2015.

[5] G. Filardo, H. Madry, M. Jelic, A. Roffi, M. Cucchiarini, and E. Kon, "Mesenchymal stem cells for the treatment of cartilage lesions: from preclinical findings to clinical application in orthopaedics," Knee Surgery, Sports Traumatology, Arthroscopy, vol. 21, no. 8, pp. 1717-1729, 2013.

[6] A. M. Lubis and V. K. Lubis, "Adult bone marrow stem cells in cartilage therapy," Acta Medica Indonesiana, vol. 44, no. 1, pp. 62-68, 2012.

[7] W. S. Toh, C. B. Foldager, M. Pei, and J. H. Hui, "Advances in mesenchymal stem cell-based strategies for cartilage repair and regeneration," Stem Cell Reviews and Reports, vol. 10, no. 5, pp. 686-696, 2014.

[8] R. C. Lawrence, D. T. Felson, C. G. Helmick et al., "Estimates of the prevalence of arthritis and other rheumatic conditions in the United States. Part II," Arthritis \& Rheumatology, vol. 58, no. 1, pp. 26-35, 2008.

[9] C. R. Chu, M. Szczodry, and S. Bruno, "Animal models for cartilage regeneration and repair," Tissue Engineering Part B: Reviews, vol. 16, no. 1, pp. 105-115, 2010.

[10] A. M. Alshami, "Knee osteoarthritis related pain: a narrative review of diagnosis and treatment," International Journal Health Sciences, vol. 8, no. 1, pp. 85-104, 2014.

[11] E. A. Makris, A. H. Gomoll, K. N. Malizos, H. JC, and K. A. Athanasiou, "Repair and tissue engineering techniques for articular cartilage," Nature Reviews Rheumatology, vol. 11, no. 1, pp. 21-34, 2015.

[12] K. Gopal, H. A. Amirhamed, and T. Kamarul, "Advances of human bone marrow-derived mesenchymal stem cells in the treatment of cartilage defects: a systematic review," Experimental Biology and Medicine, vol. 239, no. 6, pp. 663-669, 2014.

[13] J. Withrow, C. Murphy, Y. Liu, M. Hunter, S. Fulzele, and M. W. Hamrick, "Extracellular vesicles in the pathogenesis of rheumatoid arthritis and osteoarthritis," Arthritis Research \& Therapy, vol. 18, no. 1, p. 286, 2016.

[14] J. Y. Ko, K. I. Kim, S. Park, and G. I. Im, "In vitro chondrogenesis and in vivo repair of osteochondral defect with human induced pluripotent stem cells," Biomaterials, vol. 35, no. 11, pp. 3571-3581, 2014.

[15] J. Li and M. Pei, "Cell senescence: a challenge in cartilage engineering and regeneration," Tissue Engineering Part B: Reviews, vol. 18, no. 4, pp. 270-287, 2012.

[16] A. Goldberg, K. Mitchell, J. Soans, L. Kim, and R. Zaidi, “The use of mesenchymal stem cells for cartilage repair and regeneration: a systematic review," Journal of Orthopaedic Surgery and Research, vol. 12, no. 1, p. 39, 2017.

[17] R. S. Tuan, A. F. Chen, and B. A. Klatt, "Cartilage regeneration," Journal of the American Academy of Orthopaedic Surgeons, vol. 21, no. 5, pp. 303-311, 2013.

[18] H. Koga, L. Engebretsen, J. E. Brinchmann, T. Muneta, and I. Sekiya, "Mesenchymal stem cell-based therapy for cartilage repair: a review," Knee Surgery, Sports Traumatology, Arthroscopy, vol. 17, no. 11, pp. 1289-1297, 2009. 
[19] A. M. Mackay, S. C. Beck, J. M. Murphy, F. P. Barry, C. O. Chichester, and M. F. Pittenger, "Chondrogenic differentiation of cultured human mesenchymal stem cells from marrow," Tissue Engineering, vol. 4, no. 4, pp. 415-428, 1998.

[20] C. Qu, K. A. Puttonen, H. Lindeberg et al., "Chondrogenic differentiation of human pluripotent stem cells in chondrocyte co-culture," The International Journal of Biochemistry \& Cell Biology, vol. 45, no. 8, pp. 1802-1812, 2013.

[21] S. P. Medvedev, E. V. Grigor'eva, A. I. Shevchenko et al., "Human induced pluripotent stem cells derived from fetal neural stem cells successfully undergo directed differentiation into cartilage," Stem Cells and Development, vol. 20, no. 6, pp. 1099-1112, 2011.

[22] E. Steck, H. Bertram, R. Abel, B. Chen, A. Winter, and W. Richter, "Induction of intervertebral disc-like cells from adult mesenchymal stem cells," Stem Cells, vol. 23, no. 3, pp. 403-411, 2005.

[23] Y. Nam, Y. A. Rim, S. M. Jung, and J. H. Ju, "Cord blood cell-derived iPSCs as a new candidate for chondrogenic differentiation and cartilage regeneration," Stem Cell Research \& Therapy, vol. 8, no. 1, p. 16, 2017.

[24] C. M. Digirolamo, D. Stokes, D. Colter, D. G. Phinney, R. Class, and D. J. Prockop, "Propagation and senescence of human marrow stromal cells in culture: a simple colonyforming assay identifies samples with the greatest potential to propagate and differentiate," British Journal Haematology, vol. 107 , no. 2, pp. 275-281, 1999.

[25] A. J. Friedenstein, I. I. Piatetzky-Shapiro, and K. V. Petrakova, "Osteogenesis in transplants of bone marrow cells," Journal of Embryology and Experimental Morphology, vol. 16, no. 3, pp. 181-190, 1966.

[26] P. A. Zuk, M. Zhu, P. Ashjian et al., "Human adipose tissue is a source of multipotent stem cells," Molecular Biology of the Cell, vol. 13, no. 12, pp. 4279-4295, 2002.

[27] K. Igura, X. Zhang, K. Takahashi, A. Mitsuru, S. Yamaguchi, and T. A. Takashi, "Isolation and characterization of mesenchymal progenitor cells from chorionic villi of human placenta," Cytotherapy, vol. 6, no. 6, pp. 543-553, 2004.

[28] T. Nagamura-Inoue and H. He, "Umbilical cord-derived mesenchymal stem cells: their advantages and potential clinical utility," World Journal of Stem Cells, vol. 6, no. 2, pp. 195-202, 2014.

[29] S. Gronthos, M. Mankani, J. Brahim, P. G. Robey, and S. Shi, "Postnatal human dental pulp stem cells (DPSCs) in vitro and in vivo," Proceedings of the National Academy of Sciences of the United States of America, vol. 97, no. 25, pp. 1362513630, 2000.

[30] P. Hilkens, P. Gervois, Y. Fanton et al., "Effect of isolation methodology on stem cell properties and multilineage differentiation potential of human dental pulp stem cells," Cell and Tissue Research, vol. 353, no. 1, pp. 65-78, 2013.

[31] I. Kassis, L. Zangi, R. Rivkin et al., "Isolation of mesenchymal stem cells from G-CSF-mobilized human peripheral blood using fibrin microbeads," Bone Marrow Transplantation, vol. 37, no. 10, pp. 967-976, 2006.

[32] C. De Bari, F. Dell'Accio, P. Tylzanowski, and F. P. Luyten, "Multipotent mesenchymal stem cells from adult human synovial membrane," Arthritis \& Rheumatology, vol. 44, no. 8, pp. 1928-1942, 2001.

[33] M. Dominici, K. Le Blanc, I. Mueller et al., "Minimal criteria for defining multipotent mesenchymal stromal cells. The international society for cellular therapy position statement," Cytotherapy, vol. 8, no. 4, pp. 315-317, 2006.

[34] S. Aggarwal and M. F. Pittenger, "Human mesenchymal stem cells modulate allogeneic immune cell responses," Blood, vol. 105, no. 4, pp. 1815-1822, 2005.

[35] A. M. DeLise, L. Fischer, and R. S. Tuan, "Cellular interactions and signaling in cartilage development," Osteoarthritis and Cartilage, vol. 8, no. 5, pp. 309-334, 2000.

[36] J. U. Yoo, T. S. Barthel, K. Nishimura et al., "The chondrogenic potential of human bone-marrow-derived mesenchymal progenitor cells," The Journal of Bone \& Joint Surgery, vol. 80, no. 12, pp. 1745-1757, 1998.

[37] E. J. Kubosch, E. Heidt, A. Bernstein, K. Böttiger, and H. Schmal, "The trans-well coculture of human synovial mesenchymal stem cells with chondrocytes leads to selforganization, chondrogenic differentiation, and secretion of TGF $\beta$," Stem Cell Research \& Therapy, vol. 7, no. 1, p. 64, 2016.

[38] X. Li, L. Duan, Y. Liang, W. Zhu, J. Xiong, and D. Wang, "Human umbilical cord blood-derived mesenchymal stem cells contribute to chondrogenesis in coculture with chondrocytes," BioMed Research International, vol. 2016, Article ID 3827057, 2 pages, 2016.

[39] C. Acharya, A. Adesida, P. Zajac et al., "Enhanced chondrocyte proliferation and mesenchymal stromal cells chondrogenesis in coculture pellets mediate improved cartilage formation," Journal of Cellular Physiology, vol. 227, no. 1, pp. 88-97, 2012.

[40] T. Fukumoto, J. W. Sperling, A. Sanyal et al., "Combined effects of insulin-like growth factor-1 and transforming growth factor- $\beta 1$ on periosteal mesenchymal cells during chondrogenesis in vitro," Osteoarthritis and Cartilage, vol. 11, no. 1, pp. 55-64, 2003.

[41] L. A. Solchaga, K. Penick, J. D. Porter, V. M. Goldberg, A. I. Caplan, and J. F. Welter, "FGF-2 enhances the mitotic and chondrogenic potentials of human adult bone marrowderived mesenchymal stem cells," Journal of Cellular Physiology, vol. 203, no. 2, pp. 398-409, 2005.

[42] H. J. Kim, Y. J. Kim, and G. I. Im, "Is continuous treatment with transforming growth factor-beta necessary to induce chondrogenic differentiation in mesenchymal stem cells?," Cells, Tissues, Organs, vol. 190, no. 1, pp. 1-10, 2009.

[43] I. Sekiya, B. L. Larson, J. T. Vuoristo, R. L. Reger, and D. J. Prockop, "Comparison of effect of BMP-2, -4, and -6 on in vitro cartilage formation of human adult stem cells from bone marrow stroma," Cell and Tissue Research, vol. 320, no. 2, pp. 269-276, 2005.

[44] D. Xu, Z. Gechtman, A. Hughes et al., "Potential involvement of BMP receptor type IB activation in a synergistic effect of chondrogenic promotion between rhTGF $\beta 3$ and rhGDF5 or rhBMP7 in human mesenchymal stem cells," Growth Factors, vol. 24, no. 4, pp. 268-278, 2006.

[45] T. Gomez-Leduc, M. Hervieu, F. Legendre et al., "Chondrogenic commitment of human umbilical cord blood-derived mesenchymal stem cells in collagen matrices for cartilage engineering," Scientific Reports, vol. 6, no. 1, article 32786, 2016.

[46] E. Arslan, M. O. Guler, and A. B. Tekinay, "Glycosaminoglycan-mimetic signals direct the osteo/chondrogenic differentiation of mesenchymal stem cells in a three-dimensional peptide nanofiber extracellular matrix mimetic environment," Biomacromolecules, vol. 17, no. 4, pp. 1280-1291, 2016. 
[47] C. Y. Fong, A. Subramanian, K. Gauthaman et al., "Human umbilical cord Wharton's jelly stem cells undergo enhanced chondrogenic differentiation when grown on nanofibrous scaffolds and in a sequential two-stage culture medium environment," Stem Cell Reviews and Reports, vol. 8, no. 1, pp. 195-209, 2012.

[48] W. J. Li, R. Tuli, C. Okafor et al., "A three-dimensional nanofibrous scaffold for cartilage tissue engineering using human mesenchymal stem cells," Biomaterials, vol. 26, no. 6, pp. 599-609, 2005.

[49] D. Bosnakovski, M. Mizuno, G. Kim, S. Takagi, M. Okumura, and T. Fujinaga, "Chondrogenic differentiation of bovine bone marrow mesenchymal stem cells (MSCs) in different hydrogels: influence of collagen type II extracellular matrix on MSC chondrogenesis," Biotechnology and Bioengineering, vol. 93, no. 6, pp. 1152-1163, 2006.

[50] H. Yao, J. Xue, Q. Wang et al., "Glucosamine-modified polyethylene glycol hydrogel-mediated chondrogenic differentiation of human mesenchymal stem cells," Materials Science and Engineering: C, vol. 79, pp. 661-670, 2017.

[51] W. Wang, B. Li, Y. Li, Y. Jiang, H. Ouyang, and C. Gao, "In vivo restoration of full-thickness cartilage defects by poly(lactide-co-glycolide) sponges filled with fibrin gel, bone marrow mesenchymal stem cells and DNA complexes," Biomaterials, vol. 31, no. 23, pp. 5953-5965, 2010.

[52] S. Liu, Y. Jia, M. Yuan et al., "Repair of osteochondral defects using human umbilical cord Wharton's jelly-derived mesenchymal stem cells in a rabbit model," BioMed Research International, vol. 2017, Article ID 8760383, 12 pages, 2017.

[53] J. Leijten, N. Georgi, L. Moreira Teixeira, C. A. van Blitterswijk, J. N. Post, and M. Karperien, "Metabolic programming of mesenchymal stromal cells by oxygen tension directs chondrogenic cell fate," Proceedings of the National Academy of Sciences of the United States of America, vol. 111, no. 38, pp. 13954-13959, 2014.

[54] M. E. Bernardo, J. A. Emons, M. Karperien et al., "Human mesenchymal stem cells derived from bone marrow display a better chondrogenic differentiation compared with other sources," Connective Tissue Research, vol. 48, no. 3, pp. 132-140, 2007.

[55] G. I. Im, Y. W. Shin, and K. B. Lee, "Do adipose tissuederived mesenchymal stem cells have the same osteogenic and chondrogenic potential as bone marrow-derived cells?," Osteoarthritis and Cartilage, vol. 13, no. 10, pp. 845-853, 2005.

[56] L. Danišovič, M. Boháč, R. Zamborský et al., "Comparative analysis of mesenchymal stromal cells from different tissue sources in respect to articular cartilage tissue engineering," General Physiology and Biophysics, vol. 35, no. 02, pp. 207-214, 2016.

[57] T. Hennig, H. Lorenz, A. Thiel et al., "Reduced chondrogenic potential of adipose tissue derived stromal cells correlates with an altered TGF $\beta$ receptor and BMP profile and is overcome by BMP-6," Journal of Cellular Physiology, vol. 211, no. 3, pp. 682-691, 2007.

[58] H. J. Kim and G. I. Im, "Chondrogenic differentiation of adipose tissue-derived mesenchymal stem cells: greater doses of growth factor are necessary," Journal of Orthopaedic Research, vol. 27, no. 5, pp. 612-619, 2009.

[59] K. Pelttari, A. Winter, E. Steck et al., "Premature induction of hypertrophy during in vitro chondrogenesis of human mesenchymal stem cells correlates with calcification and vascular invasion after ectopic transplantation in SCID mice," Arthritis \& Rheumatology, vol. 54, no. 10, pp. 3254-3266, 2006.

[60] J. M. Murphy, K. Dixon, S. Beck, D. Fabian, A. Feldman, and F. Barry, "Reduced chondrogenic and adipogenic activity of mesenchymal stem cells from patients with advanced osteoarthritis," Arthritis \& Rheumatology, vol. 46, no. 3, pp. 704-713, 2002.

[61] J. D. Kretlow, Y. Q. Jin, W. Liu et al., "Donor age and cell passage affects differentiation potential of murine bone marrowderived stem cells," BMC Cell Biology, vol. 9, no. 1, p. 60, 2008.

[62] A. C. Bakker, F. A. van de Loo, H. M. van Beuningen et al., "Overexpression of active TGF-beta-1 in the murine knee joint: evidence for synovial-layer-dependent chondroosteophyte formation," Osteoarthritis and Cartilage, vol. 9, no. 2, pp. 128-136, 2001.

[63] A. Scharstuhl, E. L. Vitters, P. M. van der Kraan, and W. B. van den Berg, "Reduction of osteophyte formation and synovial thickening by adenoviral overexpression of transforming growth factor $\beta$ /bone morphogenetic protein inhibitors during experimental osteoarthritis," Arthritis \& Rheumatology, vol. 48, no. 12, pp. 3442-3451, 2003.

[64] Y. Li, T. Liu, N. Van Halm-Lutterodt, J. Chen, Q. Su, and Y. Hai, "Reprogramming of blood cells into induced pluripotent stem cells as a new cell source for cartilage repair," Stem Cell Research \& Therapy, vol. 7, no. 1, p. 31, 2016.

[65] Y. Wei, W. Zeng, R. Wan et al., "Chondrogenic differentiation of induced pluripotent stem cells from osteoarthritic chondrocytes in alginate matrix," European Cells and Materials, vol. 23, pp. 1-12, 2012.

[66] R. M. Guzzo, V. Scanlon, A. Sanjay, X. RH, and H. Drissi, "Establishment of human cell type-specific iPS cells with enhanced chondrogenic potential," Stem Cell Reviews and Reports, vol. 10, no. 6, pp. 820-829, 2014.

[67] K. Kim, R. Zhao, A. Doi et al., "Donor cell type can influence the epigenome and differentiation potential of human induced pluripotent stem cells," Nature Biotechnology, vol. 29, no. 12, pp. 1117-1119, 2011.

[68] R. M. Guzzo, J. Gibson, X. RH, F. Y. Lee, and H. Drissi, "Efficient differentiation of human iPSC-derived mesenchymal stem cells to chondroprogenitor cells," Journal of Cellular Biochemistry, vol. 114, no. 2, pp. 480-490, 2013.

[69] H. Nejadnik, S. Diecke, O. D. Lenkov et al., "Improved approach for chondrogenic differentiation of human induced pluripotent stem cells," Stem Cell Reviews and Reports, vol. 11, no. 2, pp. 242-253, 2015.

[70] N. Koyama, M. Miura, K. Nakao et al., "Human induced pluripotent stem cells differentiated into chondrogenic lineage via generation of mesenchymal progenitor cells," Stem Cells and Development, vol. 22, no. 1, pp. 102-113, 2013.

[71] J. Liu, H. Nie, Z. Xu et al., "The effect of 3D nanofibrous scaffolds on the chondrogenesis of induced pluripotent stem cells and their application in restoration of cartilage defects," PLoS One, vol. 9, no. 11, article e111566, 2014.

[72] R. Kang, Y. Zhou, S. Tan et al., "Mesenchymal stem cells derived from human induced pluripotent stem cells retain adequate osteogenicity and chondrogenicity but less adipogenicity," Stem Cell Research \& Therapy, vol. 6, no. 1, p. 144, 2015.

[73] T. Zhao, Z. N. Zhang, Z. Rong, and Y. Xu, "Immunogenicity of induced pluripotent stem cells," Nature, vol. 474, no. 7350, pp. 212-215, 2011. 
[74] T. Saito, F. Yano, D. Mori et al., "Hyaline cartilage formation and tumorigenesis of implanted tissues derived from human induced pluripotent stem cells," Biomedical Research, vol. 36, no. 3, pp. 179-186, 2015.

[75] A. S. Lee, C. Tang, M. S. Rao, I. L. Weissman, and J. C. Wu, "Tumorigenicity as a clinical hurdle for pluripotent stem cell therapies," Nature Medicine, vol. 19, no. 8, pp. 998-1004, 2013.

[76] K. Okita, T. Ichisaka, and S. Yamanaka, "Generation of germline-competent induced pluripotent stem cells," Nature, vol. 448, no. 7151, pp. 313-317, 2007.

[77] M. Nakagawa, M. Koyanagi, K. Tanabe et al., "Generation of induced pluripotent stem cells without Myc from mouse and human fibroblasts," Nature Biotechnology, vol. 26, no. 1, pp. 101-106, 2008.

[78] N. Fusaki, H. Ban, A. Nishiyama, K. Saeki, and M. Hasegawa, "Efficient induction of transgene-free human pluripotent stem cells using a vector based on Sendai virus, an RNA virus that does not integrate into the host genome," Proceedings of the Japan Academy, Series B, vol. 85, no. 8, pp. 348-362, 2009.

[79] G. Itakura, S. Kawabata, M. Ando et al., "Fail-safe system against potential tumorigenicity after transplantation of iPSC derivatives," Stem Cell Reports, vol. 8, no. 3, pp. 673-684, 2017.

[80] S. Wu, Y. Wu, X. Zhang, and M. R. Capecchi, "Efficient germline transmission obtained with transgene-free induced pluripotent stem cells," Proceedings of the National Academy of Sciences of the United States of America, vol. 111, no. 29, pp. 10678-10683, 2014.

[81] M. Schuldiner, J. Itskovitz-Eldor, and N. Benvenisty, "Selective ablation of human embryonic stem cells expressing a "suicide" gene," Stem Cells, vol. 21, no. 3, pp. 257-265, 2003.

[82] C. Leten, V. D. Roobrouck, T. Struys et al., "Controlling and monitoring stem cell safety in vivo in an experimental rodent model," Stem Cells, vol. 32, no. 11, pp. 2833-2844, 2014.

[83] B. Sadlik, G. Jaroslawski, D. Gladysz et al., "Knee cartilage regeneration with umbilical cord mesenchymal stem cells embedded in collagen scaffold using dry arthroscopy technique," Advances in Experimental Medicine and Biology, vol. 1020, pp. 113-122, 2017.

[84] J. Mak, C. L. Jablonski, C. A. Leonard et al., "Intra-articular injection of synovial mesenchymal stem cells improves cartilage repair in a mouse injury model," Scientific Reports, vol. 6, no. 1, article 23076, 2016.

[85] M. F. Pittenger, A. M. Mackay, S. C. Beck et al., "Multilineage potential of adult human mesenchymal stem cells," Science, vol. 284, no. 5411, pp. 143-147, 1999.

[86] F. P. Barry and J. M. Murphy, "Mesenchymal stem cells: clinical applications and biological characterization," The International Journal of Biochemistry \& Cell Biology, vol. 36, no. 4, pp. 568-584, 2004.

[87] F. Barry, R. E. Boynton, B. Liu, and J. M. Murphy, "Chondrogenic differentiation of mesenchymal stem cells from bone marrow: differentiation-dependent gene expression of matrix components," Experimental Cell Research, vol. 268, no. 2, pp. 189-200, 2001.

[88] Y. Zhu, X. Wu, Y. Liang et al., "Repair of cartilage defects in osteoarthritis rats with induced pluripotent stem cell derived chondrocytes," BMC Biotechnology, vol. 16, no. 1, p. 78, 2016.
[89] J. M. Murphy, D. J. Fink, E. B. Hunziker, and F. P. Barry, "Stem cell therapy in a caprine model of osteoarthritis," Arthritis \& Rheumatology, vol. 48, no. 12, pp. 3464-3474, 2003.

[90] S. M. Richardson, G. Kalamegam, P. N. Pushparaj et al., "Mesenchymal stem cells in regenerative medicine: focus on articular cartilage and intervertebral disc regeneration," Methods, vol. 99, pp. 69-80, 2016.

[91] J. L. Spees, R. H. Lee, and C. A. Gregory, "Mechanisms of mesenchymal stem/stromal cell function," Stem Cell Research \& Therapy, vol. 7, no. 1, p. 125, 2016.

[92] B. E. Bobick, F. H. Chen, A. M. Le, and R. S. Tuan, "Regulation of the chondrogenic phenotype in culture," Birth Defects Research Part C, Embryo Today: Reviews, vol. 87, no. 4, pp. 351-371, 2009.

[93] K. Kuroda, T. Kabata, K. Hayashi et al., "The paracrine effect of adipose-derived stem cells inhibits osteoarthritis progression," BMC Musculoskeletal Disorders, vol. 16, no. 1, p. 236, 2015.

[94] S. Zhang, W. C. Chu, R. C. Lai, S. K. Lim, J. H. Hui, and W. S. Toh, "Exosomes derived from human embryonic mesenchymal stem cells promote osteochondral regeneration," Osteoarthritis and Cartilage, vol. 24, no. 12, pp. 2135-2140, 2016.

[95] S. C. Tao, T. Yuan, Y. L. Zhang, W. J. Yin, S. C. Guo, and C. Q. Zhang, "Exosomes derived from miR-140-5p-overexpressing human synovial mesenchymal stem cells enhance cartilage tissue regeneration and prevent osteoarthritis of the knee in a rat model," Theranostics, vol. 7, no. 1, pp. 180-195, 2017.

[96] U. T. Arasu, R. Karna, K. Harkonen et al., "Human mesenchymal stem cells secrete hyaluronan-coated extracellular vesicles," Matrix Biology, vol. 64, pp. 54-68, 2017.

[97] A. Uccelli, L. Moretta, and V. Pistoia, "Mesenchymal stem cells in health and disease," Nature Reviews Immunology, vol. 8, no. 9, pp. 726-736, 2008.

[98] G. Chamberlain, J. Fox, B. Ashton, and J. Middleton, "Concise review: mesenchymal stem cells: their phenotype, differentiation capacity, immunological features, and potential for homing," Stem Cells, vol. 25, no. 11, pp. 2739-2749, 2007.

[99] Y. M. Pers, M. Ruiz, D. Noel, and C. Jorgensen, "Mesenchymal stem cells for the management of inflammation in osteoarthritis: state of the art and perspectives," Osteoarthritis and Cartilage, vol. 23, no. 11, pp. 2027-2035, 2015.

[100] S. Glennie, I. Soeiro, P. J. Dyson, E. W. Lam, and F. Dazzi, "Bone marrow mesenchymal stem cells induce division arrest anergy of activated T cells," Blood, vol. 105, no. 7, pp. 28212827, 2005.

[101] A. Del Fattore, R. Luciano, L. Pascucci et al., "Immunoregulatory effects of mesenchymal stem cell-derived extracellular vesicles on T lymphocytes," Cell Transplantation, vol. 24, no. 12, pp. 2615-2627, 2015.

[102] K. Akiyama, C. Chen, D. Wang et al., "Mesenchymal-stemcell-induced immunoregulation involves FAS-ligand-/FASmediated T cell apoptosis," Cell Stem Cell, vol. 10, no. 5, pp. 544-555, 2012.

[103] R. Meisel, A. Zibert, M. Laryea, U. Gobel, W. Daubener, and D. Dilloo, "Human bone marrow stromal cells inhibit allogeneic T-cell responses by indoleamine 2,3-dioxygenase-mediated tryptophan degradation," Blood, vol. 103, no. 12, pp. 4619-4621, 2004. 
[104] W. Ge, J. Jiang, J. Arp, W. Liu, B. Garcia, and H. Wang, "Regulatory T-cell generation and kidney allograft tolerance induced by mesenchymal stem cells associated with indoleamine 2,3-dioxygenase expression," Transplantation, vol. 90, no. 12, pp. 1312-1320, 2010.

[105] G. M. Spaggiari, A. Capobianco, H. Abdelrazik, F. Becchetti, M. C. Mingari, and L. Moretta, "Mesenchymal stem cells inhibit natural killer-cell proliferation, cytotoxicity, and cytokine production: role of indoleamine 2,3-dioxygenase and prostaglandin E2," Blood, vol. 111, no. 3, pp. 1327-1333, 2008.

[106] L. Pierdomenico, L. Bonsi, M. Calvitti et al., "Multipotent mesenchymal stem cells with immunosuppressive activity can be easily isolated from dental pulp," Transplantation, vol. 80, no. 6, pp. 836-842, 2005.

[107] P. C. Demircan, A. E. Sariboyaci, Z. S. Unal, G. Gacar, C. Subasi, and E. Karaoz, "Immunoregulatory effects of human dental pulp-derived stem cells on T cells: comparison of transwell co-culture and mixed lymphocyte reaction systems," Cytotherapy, vol. 13, no. 10, pp. 1205-1220, 2011.

[108] R. Ramasamy, H. Fazekasova, E. W. Lam, I. Soeiro, G. Lombardi, and F. Dazzi, "Mesenchymal stem cells inhibit dendritic cell differentiation and function by preventing entry into the cell cycle," Transplantation, vol. 83, no. 1, pp. 71-76, 2007.

[109] A. J. Nauta, A. B. Kruisselbrink, E. Lurvink, R. Willemze, and W. E. Fibbe, "Mesenchymal stem cells inhibit generation and function of both $\mathrm{CD} 34^{+}$-derived and monocyte-derived dendritic cells," The Journal of Immunology, vol. 177, no. 4, pp. 2080-2087, 2006.

[110] S. Jose, S. W. Tan, Y. Y. Ooi, R. Ramasamy, and S. Vidyadaran, "Mesenchymal stem cells exert antiproliferative effect on lipopolysaccharide-stimulated BV2 microglia by reducing tumour necrosis factor- $\alpha$ levels," Journal of Neuroinflammation, vol. 11, no. 1, p. 149, 2014.

[111] Z. Rahmat, S. Jose, R. Ramasamy, and S. Vidyadaran, "Reciprocal interactions of mouse bone marrow-derived mesenchymal stem cells and BV2 microglia after lipopolysaccharide stimulation," Stem Cell Research \& Therapy, vol. 4, no. 1, p. 12, 2013.

[112] B. Zhang, R. Liu, D. Shi et al., "Mesenchymal stem cells induce mature dendritic cells into a novel Jagged-2dependent regulatory dendritic cell population," Blood, vol. 113, no. 1, pp. 46-57, 2009.

[113] Q. Z. Zhang, W. R. Su, S. H. Shi et al., "Human gingivaderived mesenchymal stem cells elicit polarization of $\mathrm{m} 2$ macrophages and enhance cutaneous wound healing," Stem Cells, vol. 28, no. 10, pp. 1856-1868, 2010.

[114] A. B. Vasandan, S. Jahnavi, C. Shashank, P. Prasad, A. Kumar, and S. J. Prasanna, "Human mesenchymal stem cells program macrophage plasticity by altering their metabolic status via a $\mathrm{PGE}_{2}$-dependent mechanism," Scientific Reports, vol. 6, no. 1, article 38308, 2016.

[115] C. Lo Sicco, D. Reverberi, C. Balbi et al., "Mesenchymal stem cell-derived extracellular vesicles as mediators of antiinflammatory effects: endorsement of macrophage polarization," Stem Cells Translational Medicine, vol. 6, no. 3, pp. 1018-1028, 2017.

[116] A. Corcione, F. Benvenuto, E. Ferretti et al., "Human mesenchymal stem cells modulate B-cell functions," Blood, vol. 107, no. 1, pp. 367-372, 2006.
[117] M. Franquesa, M. J. Hoogduijn, O. Bestard, and J. M. Grinyo, "Immunomodulatory effect of mesenchymal stem cells on B cells," Frontiers in Immunology, vol. 3, p. 212, 2012.

[118] L. V. Schnabel, C. M. Abratte, J. C. Schimenti et al., "Induced pluripotent stem cells have similar immunogenic and more potent immunomodulatory properties compared with bone marrow-derived stromal cells in vitro," Regenerative Medicine, vol. 9, no. 5, pp. 621-635, 2014.

[119] B. L. Yen, C. J. Chang, K. J. Liu et al., "Brief report-human embryonic stem cell-derived mesenchymal progenitors possess strong immunosuppressive effects toward natural killer cells as well as T lymphocytes," Stem Cells, vol. 27, no. 2, pp. 451-456, 2009.

[120] Z. Tan, Z. Y. Su, R. R. Wu et al., "Immunomodulative effects of mesenchymal stem cells derived from human embryonic stem cells in vivo and in vitro," Journal of Zhejiang University Science B, vol. 12, no. 1, pp. 18-27, 2011.

[121] Q. L. Fu, Y. Y. Chow, S. J. Sun et al., "Mesenchymal stem cells derived from human induced pluripotent stem cells modulate T-cell phenotypes in allergic rhinitis," Allergy, vol. 67, no. 10, pp. 1215-1222, 2012.

[122] H. K. Tam, A. Srivastava, C. W. Colwell, and D. D. D'Lima, "In vitro model of full-thickness cartilage defect healing," Journal of Orthopaedic Research, vol. 25, no. 9, pp. 11361144, 2007.

[123] K. W. Ng, F. Wanivenhaus, T. Chen et al., "A novel macroporous polyvinyl alcohol scaffold promotes chondrocyte migration and interface formation in an in vitro cartilage defect model," Tissue Engineering Part A, vol. 18, no. 11-12, pp. 1273-1281, 2012.

[124] C. J. Moran, A. Ramesh, P. A. Brama, J. M. O'Byrne, F. J. O'Brien, and T. J. Levingstone, "The benefits and limitations of animal models for translational research in cartilage repair," Journal of Experimental Orthopaedics, vol. 3, no. 1, p. $1,2016$.

[125] J. L. Cook, C. T. Hung, K. Kuroki et al., “Animal models of cartilage repair," Bone \& Joint Research, vol. 3, no. 4, pp. 89-94, 2014.

[126] J. D. Gibson, M. B. O'Sullivan, F. Alaee et al., "Regeneration of articular cartilage by human ESC-derived mesenchymal progenitors treated sequentially with BMP-2 and Wnt5a," Stem Cells Translational Medicine, vol. 6, no. 1, pp. 40-50, 2017.

[127] Y. Oshima, N. Watanabe, K. Matsuda, S. Takai, M. Kawata, and T. Kubo, "Behavior of transplanted bone marrowderived GFP mesenchymal cells in osteochondral defect as a simulation of autologous transplantation," Journal of Histochemistry \& Cytochemistry, vol. 53, no. 2, pp. 207-216, 2005.

[128] M. Ferretti, K. G. Marra, K. Kobayashi, A. J. Defail, and C. R. $\mathrm{Chu}$, "Controlled in vivo degradation of genipin crosslinked polyethylene glycol hydrogels within osteochondral defects," Tissue Engineering, vol. 12, no. 9, pp. 2657-2663, 2006.

[129] P. E. Lammi, M. J. Lammi, R. H. Tammi, H. J. Helminen, and M. M. Espanha, "Strong hyaluronan expression in the fullthickness rat articular cartilage repair tissue," Histochemistry and Cell Biology, vol. 115, no. 4, pp. 301-308, 2001.

[130] M. Karakaplan, N. Elmalı, E. Mirel, N. Şahin, E. Ergen, and C. Elmal1, "Effect of microfracture and autologousconditioned plasma application in the focal full-thickness chondral defect of the knee: an experimental study on rabbits," Journal of Orthopaedic Surgery and Research, vol. 10, no. 1, p. 110, 2015. 
[131] R. Vayas, R. Reyes, M. Rodríguez-Évora, C. Del Rosario, A. Delgado, and C. Évora, "Evaluation of the effectiveness of a bMSC and BMP-2 polymeric trilayer system in cartilage repair," Biomedical Materials, vol. 12, no. 4, article 045001, 2017.

[132] X. Xu, D. Shi, Y. Liu et al., "In vivo repair of full-thickness cartilage defect with human iPSC-derived mesenchymal progenitor cells in a rabbit model," Experimental and Therapeutic Medicine, vol. 14, no. 1, pp. 239-245, 2017.

[133] D. D. Frisbie, M. W. Cross, and C. W. McIlwraith, “A comparative study of articular cartilage thickness in the stifle of animal species used in human pre-clinical studies compared to articular cartilage thickness in the human knee," Veterinary and Comparative Orthopaedics and Traumatology, vol. 19, no. 3, pp. 142-146, 2006.

[134] J. Malda, J. C. de Grauw, K. E. Benders et al., "Of mice, men and elephants: the relation between articular cartilage thickness and body mass," PLoS One, vol. 8, no. 2, article e57683, 2013.

[135] D. L. Gushue, J. Houck, and A. L. Lerner, "Rabbit knee joint biomechanics: motion analysis and modeling of forces during hopping," Journal of Orthopaedic Research, vol. 23, no. 4, pp. 735-742, 2005.

[136] A. Chevrier, A. S. Kouao, G. Picard, M. B. Hurtig, and M. D. Buschmann, "Interspecies comparison of subchondral bone properties important for cartilage repair," Journal of Orthopaedic Research, vol. 33, no. 1, pp. 63-70, 2015.

[137] X. Wei, J. Gao, and K. Messner, "Maturation-dependent repair of untreated osteochondral defects in the rabbit knee joint," Journal of Biomedical Materials Research, vol. 34, no. 1, pp. 63-72, 1997.

[138] T. Möller, M. Amoroso, D. Hägg et al., "In vivo chondrogenesis in 3D bioprinted human cell-laden hydrogel constructs," Plastic and Reconstructive Surgery - Global Open, vol. 5, no. 2, article e1227, 2017.

[139] A. Haisch, A. Gröger, C. Radke et al., "Macroencapsulation of human cartilage implants: pilot study with polyelectrolyte complex membrane encapsulation," Biomaterials, vol. 21, no. 15 , pp. 1561-1566, 2000.

[140] T. Matsumoto, S. Kubo, L. B. Meszaros et al., “The influence of sex on the chondrogenic potential of muscle-derived stem cells: implications for cartilage regeneration and repair," Arthritis \& Rheumatology, vol. 58, no. 12, pp. 3809-3819, 2008.

[141] C. W. McIlwraith, D. D. Frisbie, W. G. Rodkey et al., "Evaluation of intra-articular mesenchymal stem cells to augment healing of microfractured chondral defects," Arthroscopy, vol. 27, no. 11, pp. 1552-1561, 2011.

[142] M. M. Wilke, D. V. Nydam, and A. J. Nixon, "Enhanced early chondrogenesis in articular defects following arthroscopic mesenchymal stem cell implantation in an equine model," Journal Orthopaedic Research, vol. 25, no. 7, pp. 913-925, 2007.

[143] D. D. Frisbie, H. E. McCarthy, C. W. Archer, M. F. Barrett, and C. W. McIlwraith, "Evaluation of articular cartilage progenitor cells for the repair of articular defects in an equine model," The Journal of Bone and Joint Surgery, vol. 97, no. 6, pp. 484-493, 2015.

[144] D. Kazemi, K. Shams Asenjan, N. Dehdilani, and H. Parsa, "Canine articular cartilage regeneration using mesenchymal stem cells seeded on platelet rich fibrin: macroscopic and histological assessments," Bone \& Joint Research, vol. 6, no. 2, pp. 98-107, 2017.

[145] C. D. Hoemann, M. Hurtig, E. Rossomacha et al., "Chitosanglycerol phosphate/blood implants improve hyaline cartilage repair in ovine microfracture defects," The Journal of Bone and Joint Surgery. American Volume, vol. 87, no. 12, pp. 2671-2686, 2005.

[146] N. Hopper, J. Wardale, R. Brooks, J. Power, N. Rushton, and F. Henson, "Peripheral blood mononuclear cells enhance cartilage repair in in vivo osteochondral defect model," PLoS One, vol. 10, no. 8, article e0133937, 2015.

[147] P. Orth, H. L. Meyer, L. Goebel et al., "Improved repair of chondral and osteochondral defects in the ovine trochlea compared with the medial condyle," Journal of Orthopaedic Research, vol. 31, no. 11, pp. 1772-1779, 2013.

[148] A. R. Zorzi, E. M. Amstalden, A. M. Plepis et al., "Effect of human adipose tissue mesenchymal stem cells on the regeneration of ovine articular cartilage," International Journal of Molecular Sciences, vol. 16, no. 11, pp. 26813-26831, 2015.

[149] A. F. Manunta, P. Zedde, S. Pilicchi et al., "The use of embryonic cells in the treatment of osteochondral defects of the knee: an ovine in vivo study," Joints, vol. 04, no. 02, pp. 070-079, 2016.

[150] H. Y. Nam, P. Karunanithi, W. C. Loo et al., "The effects of staged intra-articular injection of cultured autologous mesenchymal stromal cells on the repair of damaged cartilage: a pilot study in caprine model," Arthritis Research \& Therapy, vol. 15, no. 5, article R129, 2013.

[151] T. J. Levingstone, A. Ramesh, R. T. Brady et al., "Cell-free multi-layered collagen-based scaffolds demonstrate layer specific regeneration of functional osteochondral tissue in caprine joints," Biomaterials, vol. 87, pp. 69-81, 2016.

[152] B. B. Christensen, C. B. Foldager, M. L. Olesen et al., "Experimental articular cartilage repair in the Göttingen minipig: the influence of multiple defects per knee," Journal of Experimental Orthopaedics, vol. 2, no. 1, p. 13, 2015.

[153] T. Gotterbarm, S. J. Breusch, U. Schneider, and M. Jung, "The minipig model for experimental chondral and osteochondral defect repair in tissue engineering: retrospective analysis of 180 defects," Laboratory Animals, vol. 42, no. 1, pp. 71-82, 2008.

[154] M. B. Fisher, N. S. Belkin, A. H. Milby et al., "Effects of mesenchymal stem cell and growth factor delivery on cartilage repair in a mini-pig model," Cartilage, vol. 7, no. 2, pp. 174-184, 2016.

[155] C. W. Ha, Y. B. Park, J. Y. Chung, and Y. G. Park, "Cartilage repair using composites of human umbilical cord bloodderived mesenchymal stem cells and hyaluronic acid hydrogel in a minipig model," Stem Cells Translational Medicine, vol. 4, no. 9, pp. 1044-1051, 2015.

[156] B. L. Proffen, M. McElfresh, B. C. Fleming, and M. M. Murray, "A comparative anatomical study of the human knee and six animal species," The Knee, vol. 19, no. 4, pp. 493-499, 2012.

[157] J. M. Vandeweerd, N. Kirschvink, B. Muylkens et al., “A study of the anatomy and injection techniques of the ovine stifle by positive contrast arthrography, computed tomography arthrography and gross anatomical dissection," The Veterinary Journal, vol. 193, no. 2, pp. 426-432, 2012.

[158] G. Osterhoff, S. Löffler, H. Steinke, C. Feja, C. Josten, and P. Hepp, "Comparative anatomical measurements of osseous 
structures in the ovine and human knee," The Knee, vol. 18, no. 2, pp. 98-103, 2011.

[159] B. J. Ahern, J. Parvizi, R. Boston, and T. P. Schaer, "Preclinical animal models in single site cartilage defect testing: a systematic review," Osteoarthritis and Cartilage, vol. 17, no. 6, pp. 705-713, 2009.

[160] H. Madry, M. Ochi, M. Cucchiarini, D. Pape, and R. Seil, "Large animal models in experimental knee sports surgery: focus on clinical translation," Journal of Experimental Orthopaedics, vol. 2, no. 1, p. 9, 2015.

[161] C. W. McIlwraith, L. A. Fortier, D. D. Frisbie, and A. J. Nixon, "Equine models of articular cartilage repair," Cartilage, vol. 2, no. 4, pp. 317-326, 2011.

[162] S. Patil, N. Steklov, L. Song, W. C. Bae, and D. D. D'Lima, "Comparative biomechanical analysis of human and caprine knee articular cartilage," The Knee, vol. 21, no. 1, pp. 119125, 2014.

[163] J. Malda, K. E. Benders, T. J. Klein et al., "Comparative study of depth-dependent characteristics of equine and human osteochondral tissue from the medial and lateral femoral condyles," Osteoarthritis and Cartilage, vol. 20, no. 10, pp. 1147-1151, 2012.

[164] B. von Rechenberg, M. K. Akens, D. Nadler et al., "Changes in subchondral bone in cartilage resurfacing-an experimental study in sheep using different types of osteochondral grafts," Osteoarthritis and Cartilage, vol. 11, no. 4, pp. 265-277, 2003.

[165] D. W. Jackson, P. A. Lalor, H. M. Aberman, and T. M. Simon, "Spontaneous repair of full-thickness defects of articular cartilage in a goat model. A preliminary study," The Journal of Bone and Joint Surgery American Volume, vol. 83-A, no. 1, pp. 53-64, 2001.

[166] M. B. Hurtig, M. D. Buschmann, L. A. Fortier et al., "Preclinical studies for cartilage repair: recommendations from the international cartilage repair society," Cartilage, vol. 2, no. 2, pp. 137-152, 2011.

[167] J. M. Vandeweerd, F. Hontoir, N. Kirschvink et al., "Prevalence of naturally occurring cartilage defects in the ovine knee," Osteoarthritis and Cartilage, vol. 21, no. 8, pp. 11251131, 2013.

[168] H. Katagiri, L. F. Mendes, and F. P. Luyten, "Definition of a critical size osteochondral knee defect and its negative effect on the surrounding articular cartilage in the rat," Osteoarthritis and Cartilage, vol. 25, no. 9, pp. 1531-1540, 2017.

[169] X. Wei and K. Messner, "Maturation-dependent durability of spontaneous cartilage repair in rabbit knee joint," Journal of Biomedical Materials Research, vol. 46, no. 4, pp. 539-548, 1999.

[170] A. I. Vasara, M. M. Hyttinen, O. Pulliainen et al., "Immature porcine knee cartilage lesions show good healing with or without autologous chondrocyte transplantation," Osteoarthritis and Cartilage, vol. 14, no. 10, pp. 1066-1074, 2006.

[171] B. D. Boyan, L. L. Tosi, R. D. Coutts et al., "Addressing the gaps: sex differences in osteoarthritis of the knee," Biology of Sex Differences, vol. 4, no. 1, p. 4, 2013.

[172] A. S. Turner, K. A. Athanasiou, C. F. Zhu, M. R. Alvis, and H. U. Bryant, "Biochemical effects of estrogen on articular cartilage in ovariectomized sheep," Osteoarthritis and Cartilage, vol. 5, no. 1, pp. 63-69, 1997.

[173] H. Huang, J. D. Skelly, D. C. Ayers, and J. Song, “Age-dependent changes in the articular cartilage and subchondral bone of C57BL/6 mice after surgical destabilization of medial meniscus," Scientific Reports, vol. 7, no. 1, article 42294, p. 17603, 2017.

[174] H. L. Ma, T. J. Blanchet, D. Peluso, B. Hopkins, E. A. Morris, and S. S. Glasson, "Osteoarthritis severity is sex dependent in a surgical mouse model," Osteoarthritis and Cartilage, vol. 15, no. 6, pp. 695-700, 2007.

[175] S. C. Faber, F. Eckstein, S. Lukasz et al., "Gender differences in knee joint cartilage thickness, volume and articular surface areas: assessment with quantitative three-dimensional MR imaging," Skeletal Radiology, vol. 30, no. 3, pp. 144-150, 2001.

[176] D. Kumar, R. B. Souza, K. Subburaj et al., "Are there sex differences in knee cartilage composition and walking mechanics in healthy and osteoarthritis populations?," Clinical Orthopaedics and Related Research, vol. 473, no. 8, pp. 2548-2558, 2015.

[177] P. C. Kreuz, S. Muller, C. Erggelet et al., "Is gender influencing the biomechanical results after autologous chondrocyte implantation?," Knee Surgery, Sports Traumatology, Arthroscopy, vol. 22, no. 1, pp. 72-79, 2014.

[178] J. E. Trachtenberg, T. N. Vo, and A. G. Mikos, "Pre-clinical characterization of tissue engineering constructs for bone and cartilage regeneration," Annals of Biomedical Engineering, vol. 43, no. 3, pp. 681-696, 2015.

[179] F. Hontoir, P. Clegg, J. F. Nisolle, S. Tew, and J. M. Vandeweerd, "Magnetic resonance compositional imaging of articular cartilage: what can we expect in veterinary medicine?," The Veterinary Journal, vol. 205, no. 1, pp. 11-20, 2015.

[180] J. F. Nisolle, B. Bihin, N. Kirschvink et al., "Prevalence of agerelated changes in ovine lumbar intervertebral discs during computed tomography and magnetic resonance imaging," Comperative Medicine, vol. 66, no. 4, pp. 300-307, 2016.

[181] P. Orth, D. Zurakowski, M. Alini, M. Cucchiarini, and H. Madry, "Reduction of sample size requirements by bilateral versus unilateral research designs in animal models for cartilage tissue engineering," Tissue Engineering Part C: Methods, vol. 19, no. 11, pp. 885-891, 2013.

[182] M. Masri, G. Lombardero, C. Velasquillo et al., "Matrixencapsulation cell-seeding technique to prevent cell detachment during arthroscopic implantation of matrix-induced autologous chondrocytes," Arthroscopy, vol. 23, no. 8, pp. 877-883, 2007.

[183] R. H. Neundorf, M. B. Lowerison, A. M. Cruz, J. J. Thomason, B. J. McEwen, and M. B. Hurtig, "Determination of the prevalence and severity of metacarpophalangeal joint osteoarthritis in thoroughbred racehorses via quantitative macroscopic evaluation," American Journal of Veterinary Research, vol. 71, no. 11, pp. 1284-1293, 2010.

[184] L. E. Craig and A. Reed, "Age-associated cartilage degeneration of the canine humeral head," Veterinary Pathology, vol. 50, no. 2, pp. 264-268, 2013.

[185] F. Hontoir, P. Clegg, V. Simon, N. Kirschvink, J. F. Nisolle, and J. M. Vandeweerd, "Accuracy of computed tomographic arthrography for assessment of articular cartilage defects in the ovine stifle," Veterinary Radiology \& Ultrasound, vol. 58, no. 5, pp. 512-523, 2017.

[186] C. A. McGibbon and C. A. Trahan, "Measurement accuracy of focal cartilage defects from MRI and correlation of MRI graded lesions with histology: a preliminary study," Osteoarthritis and Cartilage, vol. 11, no. 7, pp. 483-493, 2003. 
[187] T. M. Link, J. Neumann, and X. Li, "Prestructural cartilage assessment using MRI," Journal of Magnetic Resonance Imaging, vol. 45, no. 4, pp. 949-965, 2017.

[188] P. M. Jungmann, T. Baum, J. S. Bauer et al., "Cartilage repair surgery: outcome evaluation by using noninvasive cartilage biomarkers based on quantitative MRI techniques?," BioMed Research International, vol. 2014, Article ID 840170, 17 pages, 2014.

[189] F. Hontoir, J. F. Nisolle, H. Meurisse et al., "A comparison of 3-T magnetic resonance imaging and computed tomography arthrography to identify structural cartilage defects of the fetlock joint in the horse," The Veterinary Journal, vol. 199, no. 1, pp. 115-122, 2014.

[190] E. H. Oei, J. van Tiel, W. H. Robinson, and G. E. Gold, "Quantitative radiologic imaging techniques for articular cartilage composition: toward early diagnosis and development of disease-modifying therapeutics for osteoarthritis," Arthritis Care \& Research, vol. 66, no. 8, pp. 1129-1141, 2014.

[191] M. Shahabpour, M. Kichouh, E. Laridon, J. L. Gielen, and J. De Mey, "The effectiveness of diagnostic imaging methods for the assessment of soft tissue and articular disorders of the shoulder and elbow," European Journal of Radiology, vol. 65, no. 2, pp. 194-200, 2008.

[192] J. E. Kurkijarvi, L. Mattila, R. O. Ojala et al., "Evaluation of cartilage repair in the distal femur after autologous chondrocyte transplantation using $T_{2}$ relaxation time and dGEMRIC," Osteoarthritis and Cartilage, vol. 15, no. 4, pp. 372378, 2007.

[193] S. J. Matzat, F. Kogan, G. W. Fong, and G. E. Gold, "Imaging strategies for assessing cartilage composition in osteoarthritis," Current Rheumatology Reports, vol. 16, no. 11, p. 462, 2014.

[194] J. Endo, A. Watanabe, T. Sasho et al., "Utility of T2 mapping and dGEMRIC for evaluation of cartilage repair after allograft chondrocyte implantation in a rabbit model," Osteoarthritis and Cartilage, vol. 23, no. 2, pp. 280-288, 2015.

[195] A. Watanabe, C. Boesch, S. E. Anderson, W. Brehm, and P. Mainil Varlet, "Ability of dGEMRIC and T2 mapping to evaluate cartilage repair after microfracture: a goat study," Osteoarthritis and Cartilage, vol. 17, no. 10, pp. 1341-1349, 2009.

[196] J. van Tiel, G. Kotek, M. Reijman et al., "Is T1 $\rho$ mapping an alternative to delayed gadolinium-enhanced MR imaging of cartilage in the assessment of sulphated glycosaminoglycan content in human osteoarthritic knees? An in vivo validation study," Radiology, vol. 279, no. 2, pp. 523-531, 2016.

[197] J. Chen, F. Wang, Y. Zhang et al., "In vivo tracking of superparamagnetic iron oxide nanoparticle labeled chondrocytes in large animal model," Annals of Biomedical Engineering, vol. 40, no. 12, pp. 2568-2578, 2012.

[198] S. Ramaswamy, J. B. Greco, M. C. Uluer, Z. Zhang, K. W. Fishbein, and R. G. Spencer, "Magnetic resonance imaging of chondrocytes labeled with superparamagnetic iron oxide nanoparticles in tissue-engineered cartilage," Tissue Engineering Part A, vol. 15, no. 12, pp. 3899-3910, 2009.

[199] J. W. Bulte, "In vivo MRI cell tracking: clinical studies," American Journal of Roentgenology, vol. 193, no. 2, pp. 314-325, 2009.

[200] H. J. Je, M. G. Kim, and H. J. Kwon, "Bioluminescence assays for monitoring chondrogenic differentiation and cartilage regeneration," Sensors, vol. 17, no. 6, 2017.
[201] M. Vilalta, C. Jorgensen, I. R. Dégano et al., "Dual luciferase labelling for non-invasive bioluminescence imaging of mesenchymal stromal cell chondrogenic differentiation in demineralized bone matrix scaffolds," Biomaterials, vol. 30, no. 28, pp. 4986-4995, 2009.

[202] M. H. Vandsburger, M. Radoul, B. Cohen, and M. Neeman, "MRI reporter genes: applications for imaging of cell survival, proliferation, migration and differentiation," $N M R$ in Biomedicine, vol. 26, no. 7, pp. 872-884, 2013.

[203] J. Kaler, G. J. Wassink, and L. E. Green, "The inter- and intraobserver reliability of a locomotion scoring scale for sheep," The Veterinary Journal, vol. 180, no. 2, pp. 189-194, 2009.

[204] H. L. Shafford, P. W. Hellyer, and A. S. Turner, "Intra-articular lidocaine plus bupivacaine in sheep undergoing stifle arthrotomy," Veterinary Anaesthesia and Analgesia, vol. 31, no. 1, pp. 20-26, 2004.

[205] R. Poole, S. Blake, M. Buschmann et al., "Recommendations for the use of preclinical models in the study and treatment of osteoarthritis," Osteoarthritis and Cartilage, vol. 18, Supplement 3, pp. S10-S16, 2010.

[206] E. Teeple, G. D. Jay, K. A. Elsaid, and B. C. Fleming, “Animal models of osteoarthritis: challenges of model selection and analysis," The AAPS Journal, vol. 15, no. 2, pp. 438-446, 2013.

[207] U. Maninchedda, O. M. Lepage, M. Gangl et al., "Development of an equine groove model to induce metacarpophalangeal osteoarthritis: a pilot study on 6 horses," PLoS One, vol. 10, no. 2, article e0115089, 2015.

[208] V. G. Cuellar, J. M. Cuellar, T. Kirsch, and E. J. Strauss, "Correlation of synovial fluid biomarkers with cartilage pathology and associated outcomes in knee arthroscopy," Arthroscopy, vol. 32, no. 3, pp. 475-485, 2016.

[209] L. T. Nguyen, A. R. Sharma, C. Chakraborty, B. Saibaba, M. E. Ahn, and S. S. Lee, "Review of prospects of biological fluid biomarkers in osteoarthritis," International Journal of Molecular Sciences, vol. 18, no. 3, 2017.

[210] C. L. Blaker, E. C. Clarke, and C. B. Little, "Using mouse models to investigate the pathophysiology, treatment, and prevention of post-traumatic osteoarthritis," Journal of Orthopaedic Research, vol. 35, no. 3, pp. 424-439, 2017.

[211] D. R. Seifer, B. D. Furman, F. Guilak, S. A. Olson, S. C. Brooks 3rd, and V. B. Kraus, "Novel synovial fluid recovery method allows for quantification of a marker of arthritis in mice," Osteoarthritis and Cartilage, vol. 16, no. 12, pp. 1532-1538, 2008.

[212] L. Goebel, D. Zurakowski, A. Müller, D. Pape, M. Cucchiarini, and H. Madry, "2D and 3D MOCART scoring systems assessed by $9.4 \mathrm{~T}$ high-field MRI correlate with elementary and complex histological scoring systems in a translational model of osteochondral repair," Osteoarthritis and Cartilage, vol. 22, no. 10, pp. 1386-1395, 2014.

[213] L. Goebel, A. Müller, A. Bücker, and H. Madry, "High resolution MRI imaging at 9.4 tesla of the osteochondral unit in a translational model of articular cartilage repair," $B M C$ Musculoskeletal Disorders, vol. 16, no. 1, p. 91, 2015.

[214] P. Orth, C. Peifer, L. Goebel, M. Cucchiarini, and H. Madry, "Comprehensive analysis of translational osteochondral repair: focus on the histological assessment," Progress in Histochemistry and Cytochemistry, vol. 50, no. 3, pp. 19-36, 2015.

[215] C. B. Little, M. M. Smith, M. A. Cake, R. A. Read, M. J. Murphy, and F. P. Barry, "The OARSI histopathology initiative - recommendations for histological assessments 
of osteoarthritis in sheep and goats," Osteoarthritis and Cartilage, vol. 18, Supplement 3, pp. S80-S92, 2010.

[216] A. Changoor, N. Tran-Khanh, S. Méthot et al., "A polarized light microscopy method for accurate and reliable grading of collagen organization in cartilage repair," Osteoarthritis and Cartilage, vol. 19, no. 1, pp. 126-135, 2011.

[217] C. Hoemann, R. Kandel, S. Roberts et al., "International cartilage repair society (ICRS) recommended guidelines for histological endpoints for cartilage repair studies in animal models and clinical trials," Cartilage, vol. 2, no. 2, pp. 153-172, 2011.

[218] M. P. van den Borne, N. J. Raijmakers, J. Vanlauwe et al., "International cartilage repair society (ICRS) and Oswestry macroscopic cartilage evaluation scores validated for use in autologous chondrocyte implantation (ACI) and microfracture," Osteoarthritis and Cartilage, vol. 15, no. 12, pp. 13971402, 2007.

[219] M. Rutgers, M. J. van Pelt, W. J. Dhert, L. B. Creemers, and D. B. Saris, "Evaluation of histological scoring systems for tissue-engineered, repaired and osteoarthritic cartilage," Osteoarthritis and Cartilage, vol. 18, no. 1, pp. 12-23, 2010.

[220] P. Orth, D. Zurakowski, D. Wincheringer, and H. Madry, "Reliability, reproducibility, and validation of five major histological scoring systems for experimental articular cartilage repair in the rabbit model," Tissue Engineering Part C: Methods, vol. 18, no. 5, pp. 329-339, 2012.

[221] P. Kiviranta, E. Lammentausta, J. Töyräs, I. Kiviranta, and J. S. Jurvelin, "Indentation diagnostics of cartilage degeneration," Osteoarthritis and Cartilage, vol. 16, no. 7, pp. 796-804, 2008.

[222] C. D. Hoemann, J. Sun, V. Chrzanowski, and M. D. Buschmann, "A multivalent assay to detect glycosaminoglycan, protein, collagen, RNA, and DNA content in milligram samples of cartilage or hydrogel-based repair cartilage," Analytical Biochemistry, vol. 300, no. 1, pp. 1-10, 2002.

[223] G. P. Dowthwaite, J. C. Bishop, S. N. Redman et al., "The surface of articular cartilage contains a progenitor cell population," Journal of Cell Science, vol. 117, pp. 889-897, 2004.

[224] R. Williams, I. M. Khan, K. Richardson et al., "Identification and clonal characterisation of a progenitor cell subpopulation in normal human articular cartilage," PLoS One, vol. 5, no. 10, article e13246, 2010.

[225] Y. Yu, H. Zheng, J. A. Buckwalter, and J. A. Martin, “Single cell sorting identifies progenitor cell population from full thickness bovine articular cartilage," Osteoarthritis and Cartilage, vol. 22, no. 9, pp. 1318-1326, 2014.

[226] M. Imaizumi, Y. Nomoto, Y. Sato et al., "Evaluation of the use of induced pluripotent stem cells (iPSCs) for the regeneration of tracheal cartilage," Cell Transplantation, vol. 22, no. 2, pp. 341-353, 2013.

[227] T. D. Bornes, A. B. Adesida, and N. M. Jomha, "Mesenchymal stem cells in the treatment of traumatic articular cartilage defects: a comprehensive review," Arthritis Research \& Ther$a p y$, vol. 16, no. 5, p. 432, 2014.

[228] Z. Z. Zhang, S. J. Wang, J. Y. Zhang et al., "3D-printed poly( $\varepsilon$ caprolactone) scaffold augmented with mesenchymal stem cells for total meniscal substitution: a 12- and 24-week animal study in a rabbit model," The American Journal of Sports Medicine, vol. 45, no. 7, pp. 1497-1511, 2017.

[229] B. Sridharan, A. D. Laflin, M. A. Holtz, D. M. Pacicca, N. K. Wischmeier, and M. S. Detamore, "In vivo evaluation of stem cell aggregates on osteochondral regeneration," Journal of Orthopaedic Research, vol. 35, no. 8, pp. 1606-1616, 2016.

[230] M. Itokazu, S. Wakitani, H. Mera et al., "Transplantation of scaffold-free cartilage-like cell-sheets made from human bone marrow mesenchymal stem cells for cartilage repair: a preclinical study," Cartilage, vol. 7, no. 4, pp. 361-372, 2016.

[231] O. H. Jeon and J. Elisseeff, "Orthopedic tissue regeneration: cells, scaffolds, and small molecules," Drug Delivery and Translational Research, vol. 6, no. 2, pp. 105-120, 2016.

[232] P. Vanhelleputte, K. Nijs, M. Delforge, G. Evers, and S. Vanderschueren, "Pain during bone marrow aspiration: prevalence and prevention," Journal of Pain and Symptom Management, vol. 26, no. 3, pp. 860-866, 2003.

[233] P. A. Zuk, M. Zhu, H. Mizuno et al., "Multilineage cells from human adipose tissue: implications for cell-based therapies," Tissue Engineering, vol. 7, no. 2, pp. 211-228, 2001.

[234] D. Mehrabani, M. Babazadeh, N. Tanideh et al., "The healing effect of adipose-derived mesenchymal stem cells in fullthickness femoral articular cartilage defects of rabbit," International Journal of Organ Transplantation Medicine, vol. 6, no. 4, pp. 165-175, 2015.

[235] D. Murata, S. Tokunaga, T. Tamura et al., "A preliminary study of osteochondral regeneration using a scaffold-free three-dimensional construct of porcine adipose tissuederived mesenchymal stem cells," Journal of Orthopaedic Surgery and Research, vol. 10, no. 1, p. 35, 2015.

[236] S. Portron, C. Merceron, O. Gauthier et al., "Effects of in vitro low oxygen tension preconditioning of adipose stromal cells on their in vivo chondrogenic potential: application in cartilage tissue repair," PLoS One, vol. 8, no. 4, article e62368, 2013.

[237] P. Van Pham, K. H. Bui, D. Q. Ngo et al., "Activated platelet-rich plasma improves adipose-derived stem cell transplantation efficiency in injured articular cartilage," Stem Cell Research \& Therapy, vol. 4, no. 4, p. 91, 2013.

[238] H. Koga, T. Muneta, T. Nagase et al., "Comparison of mesenchymal tissues-derived stem cells for in vivo chondrogenesis: suitable conditions for cell therapy of cartilage defects in rabbit," Cell and Tissue Research, vol. 333, no. 2, pp. 207-215, 2008.

[239] X. Xie, Y. Wang, C. Zhao et al., "Comparative evaluation of MSCs from bone marrow and adipose tissue seeded in PRP-derived scaffold for cartilage regeneration," Biomaterials, vol. 33, no. 29, pp. 7008-7018, 2012.

[240] Q. Li, J. Tang, R. Wang et al., "Comparing the chondrogenic potential in vivo of autogeneic mesenchymal stem cells derived from different tissues," Artificial Cells, Blood Substitutes, and Immobilization Biotechnology, vol. 39, no. 1, pp. 31-38, 2011.

[241] J. C. Lee, H. J. Min, H. J. Park, S. Lee, S. C. Seong, and M. C. Lee, "Synovial membrane-derived mesenchymal stem cells supported by platelet-rich plasma can repair osteochondral defects in a rabbit model," Arthroscopy, vol. 29, no. 6, pp. 1034-1046, 2013.

[242] J. C. Lee, S. Y. Lee, H. J. Min et al., "Synovium-derived mesenchymal stem cells encapsulated in a novel injectable gel can repair osteochondral defects in a rabbit model," Tissue Engineering Part A, vol. 18, no. 19-20, pp. 2173-2186, 2012.

[243] T. Nakamura, I. Sekiya, T. Muneta et al., "Arthroscopic, histological and MRI analyses of cartilage repair after a 
minimally invasive method of transplantation of allogeneic synovial mesenchymal stromal cells into cartilage defects in pigs," Cytotherapy, vol. 14, no. 3, pp. 327-338, 2012.

[244] S. Meirelles Lda, A. M. Fontes, D. T. Covas, and A. I. Caplan, "Mechanisms involved in the therapeutic properties of mesenchymal stem cells," Cytokine \& Growth Factor Reviews, vol. 20, no. 5-6, pp. 419-427, 2009.

[245] Y. Zhang, S. Liu, W. Guo et al., "Co-culture systemsbased strategies for articular cartilage tissue engineering," Journal of Cellular Physiology, vol. 233, no. 3, pp. 19401951, 2018.

[246] M. A. Sabatino, R. Santoro, S. Gueven et al., "Cartilage graft engineering by co-culturing primary human articular chondrocytes with human bone marrow stromal cells," Journal of Tissue Engineering and Regenerative Medicine, vol. 9, no. 12, pp. 1394-1403, 2015.

[247] Z. Cai, B. Pan, H. Jiang, and L. Zhang, "Chondrogenesis of human adipose-derived stem cells by in vivo co-graft with auricular chondrocytes from microtia," Aesthetic Plastic Surgery, vol. 39, no. 3, pp. 431-439, 2015.

[248] L. Moradi, M. Vasei, M. M. Dehghan, M. Majidi, S. Farzad Mohajeri, and S. Bonakdar, "Regeneration of meniscus tissue using adipose mesenchymal stem cells-chondrocytes coculture on a hybrid scaffold: in vivo study," Biomaterials, vol. 126, pp. 18-30, 2017.

[249] K. B. Lee, J. H. Hui, I. C. Song, L. Ardany, and E. H. Lee, "Injectable mesenchymal stem cell therapy for large cartilage defects-a porcine model," Stem Cells, vol. 25, no. 11, pp. 2964-2971, 2007.

[250] H. Koga, M. Shimaya, T. Muneta et al., "Local adherent technique for transplanting mesenchymal stem cells as a potential treatment of cartilage defect," Arthritis Research \& Therapy, vol. 10, no. 4, p. R84, 2008.

[251] Y. Yasui, W. Ando, K. Shimomura et al., "Scaffold-free, stem cell-based cartilage repair," Journal of Clinical Orthopaedics and Trauma, vol. 7, no. 3, pp. 157-163, 2016.

[252] J. Xue, A. He, Y. Zhu et al., "Repair of articular cartilage defects with acellular cartilage sheets in a swine model," Biomedical Materials, 2017.

[253] Z. J. Wang, R. Z. An, J. Y. Zhao et al., "Repair of articular cartilage defects by tissue-engineered cartilage constructed with adipose-derived stem cells and acellular cartilaginous matrix in rabbits," Genetics and Molecular Research, vol. 13, no. 2, pp. 4599-4606, 2014.

[254] I. L. Kim, R. L. Mauck, and J. A. Burdick, "Hydrogel design for cartilage tissue engineering: a case study with hyaluronic acid," Biomaterials, vol. 32, no. 34, pp. 87718782, 2011.

[255] S. Kazemnejad, M. Khanmohammadi, N. Baheiraei, and S. Arasteh, "Current state of cartilage tissue engineering using nanofibrous scaffolds and stem cells," Avicenna Journal of Medical Biotechnology, vol. 9, no. 2, pp. 50-65, 2017.

[256] D. Nguyen, D. A. Hagg, A. Forsman et al., "Cartilage tissue engineering by the 3D bioprinting of iPS cells in a nanocellulose/alginate bioink," Scientific Reports, vol. 7, no. 1, p. 658, 2017.

[257] C. McKee, Y. Hong, D. Yao, and G. R. Chaudhry, "Compression induced chondrogenic differentiation of embryonic stem cells in three-dimensional polydimethylsiloxane scaffolds," Tissue Engineering Part A, vol. 23, no. 9-10, pp. 426-435, 2017.
[258] C. Chung and J. A. Burdick, "Engineering cartilage tissue," Advanced Drug Delivery Reviews, vol. 60, no. 2, pp. 243-262, 2008.

[259] M. Liu, X. Zeng, C. Ma et al., "Injectable hydrogels for cartilage and bone tissue engineering," Bone Research, vol. 5, article 17014, 2017.

[260] M. Mata, L. Milian, M. Oliver et al., "In vivo articular cartilage regeneration using human dental pulp stem cells cultured in an alginate scaffold: a preliminary study," Stem Cells International, vol. 2017, Article ID 8309256, 9 pages, 2017.

[261] C. Chung and J. A. Burdick, "Influence of three-dimensional hyaluronic acid microenvironments on mesenchymal stem cell chondrogenesis," Tissue Engineering Part A, vol. 15, no. 2, pp. 243-254, 2009.

[262] J. Y. Chung, M. Song, C. W. Ha, J. A. Kim, C. H. Lee, and Y. B. Park, "Comparison of articular cartilage repair with different hydrogel-human umbilical cord blood-derived mesenchymal stem cell composites in a rat model," Stem Cell Research \& Therapy, vol. 5, no. 2, p. 39, 2014.

[263] D. Eyrich, F. Brandl, B. Appel et al., "Long-term stable fibrin gels for cartilage engineering," Biomaterials, vol. 28, no. 1, pp. 55-65, 2007.

[264] W. Swieszkowski, B. H. Tuan, K. J. Kurzydlowski, and D. W. Hutmacher, "Repair and regeneration of osteochondral defects in the articular joints," Biomolecular Engineering, vol. 24, no. 5, pp. 489-495, 2007.

[265] C. H. Chang, T. F. Kuo, F. H. Lin et al., "Tissue engineeringbased cartilage repair with mesenchymal stem cells in a porcine model," Journal of Orthopaedic Research, vol. 29, no. 12, pp. 1874-1880, 2011.

[266] M. Lazarini, P. Bordeaux-Rego, R. Giardini-Rosa et al., "Natural type II collagen hydrogel, fibrin sealant, and adiposederived stem cells as a promising combination for articular cartilage repair," Cartilage, vol. 8, no. 4, pp. 439-443, 2017.

[267] P. Gentile, V. Chiono, I. Carmagnola, and P. V. Hatton, "An overview of poly(lactic-co-glycolic) acid (PLGA)-based biomaterials for bone tissue engineering," International Journal of Molecular Sciences, vol. 15, no. 3, pp. 3640-3659, 2014.

[268] F. Yin, J. Cai, W. Zen et al., "Cartilage regeneration of adipose-derived stem cells in the TGF- $\beta 1$-immobilized PLGA-gelatin scaffold," Stem Cell Reviews and Reports, vol. 11, no. 3, pp. 453-459, 2015.

[269] S. Zhu, B. Zhang, C. Man, Y. Ma, X. Liu, and J. Hu, "Combined effects of connective tissue growth factor-modified bone marrow-derived mesenchymal stem cells and $\mathrm{NaOH}$ treated PLGA scaffolds on the repair of articular cartilage defect in rabbits," Cell Transplantation, vol. 23, no. 6, pp. 715-727, 2014.

[270] M. Caminal, X. Moll, D. Codina et al., “Transitory improvement of articular cartilage characteristics after implantation of polylactide:polyglycolic acid (PLGA) scaffolds seeded with autologous mesenchymal stromal cells in a sheep model of critical-sized chondral defect," Biotechnology Letters, vol. 36, no. 10, pp. 2143-2153, 2014.

[271] M. Li, X. Luo, X. Lv et al., "In vivo human adipose-derived mesenchymal stem cell tracking after intra-articular delivery in a rat osteoarthritis model," Stem Cell Research \& Therapy, vol. 7, no. 1, p. 160, 2016.

[272] L. S. Tseng, S. H. Chen, M. T. Lin, and Y. C. Lin, "Transplantation of human dental pulp-derived stem cells protects 
against heatstroke in mice," Cell Transplantation, vol. 24, no. 5, pp. 921-937, 2015.

[273] I. Kerkis, C. E. Ambrosio, A. Kerkis et al., "Early transplantation of human immature dental pulp stem cells from baby teeth to golden retriever muscular dystrophy (GRMD) dogs: local or systemic?," Journal of Translational Medicine, vol. 6 , no. 1, p. 35, 2008.

[274] F. Wei, T. Song, G. Ding et al., "Functional tooth restoration by allogeneic mesenchymal stem cell-based bio-root regeneration in swine," Stem Cells and Development, vol. 22, no. 12, pp. 1752-1762, 2013.

[275] V. Dayan, V. Sotelo, V. Delfina et al., "Human mesenchymal stromal cells improve cardiac perfusion in an ovine immunocompetent animal model," Journal of Investigative Surgery, vol. 29, no. 4, pp. 218-225, 2016.

[276] J. Harding, R. M. Roberts, and O. Mirochnitchenko, "Large animal models for stem cell therapy," Stem Cell Research \& Therapy, vol. 4, no. 2, p. 23, 2013.

[277] J. Ogorevc, S. Orehek, and P. Dovc, "Cellular reprogramming in farm animals: an overview of iPSC generation in the mammalian farm animal species," Journal of Animal Science and Biotechnology, vol. 7, no. 1, p. 10, 2016.

[278] C. Madeira, A. Santhagunam, J. B. Salgueiro, and J. M. Cabral, "Advanced cell therapies for articular cartilage regeneration," Trends in Biotechnology, vol. 33, no. 1, pp. 35-42, 2015.

[279] O. S. Beane, V. C. Fonseca, L. L. Cooper, G. Koren, and E. M. Darling, "Impact of aging on the regenerative properties of bone marrow-, muscle-, and adipose-derived mesenchymal stem/stromal cells," PLoS One, vol. 9, no. 12, article e115963, 2014.

[280] Y. J. Kim, H. J. Kim, and G. I. Im, "PTHrP promotes chondrogenesis and suppresses hypertrophy from both bone marrow-derived and adipose tissue-derived MSCs," Biochemical and Biophysical Research Communications, vol. 373, no. 1, pp. 104-108, 2008.

[281] C. J. Moran, C. Pascual-Garrido, S. Chubinskaya et al., "Restoration of articular cartilage," The Journal of Bone \& Joint Surgery, vol. 96, no. 4, pp. 336-344, 2014. 


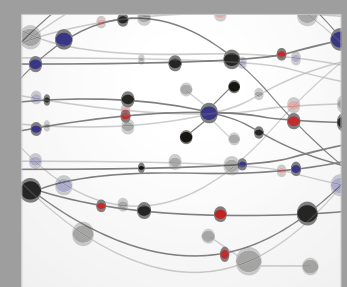

The Scientific World Journal
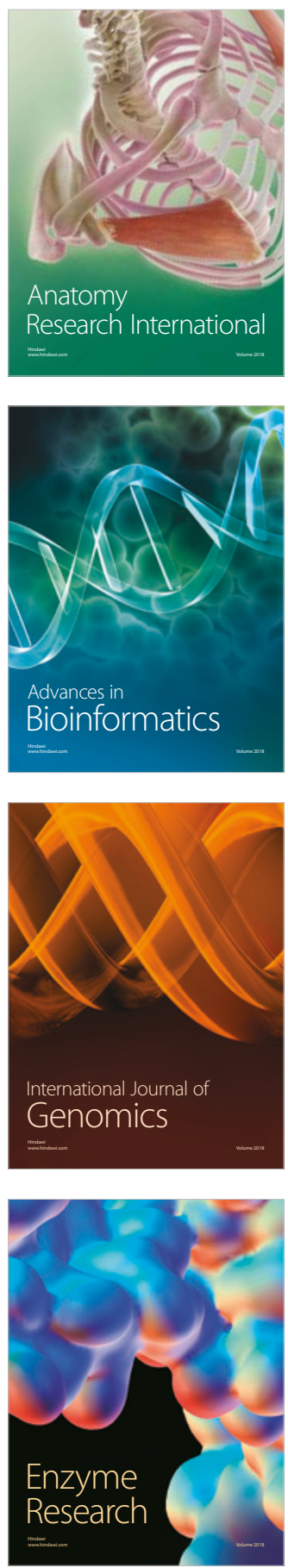
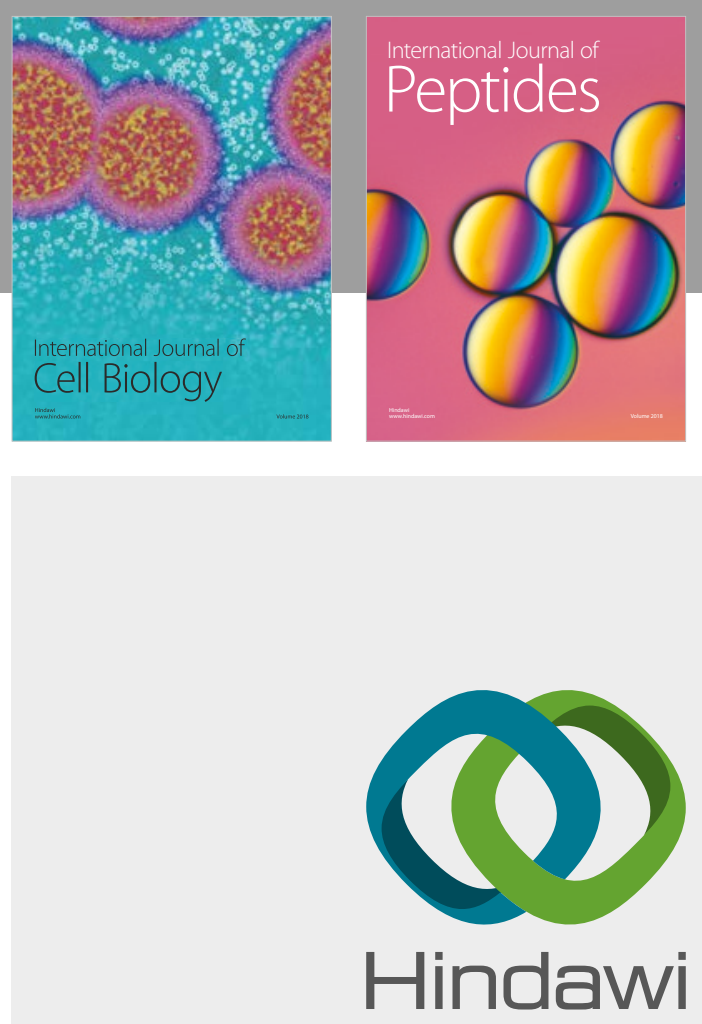

Submit your manuscripts at

www.hindawi.com
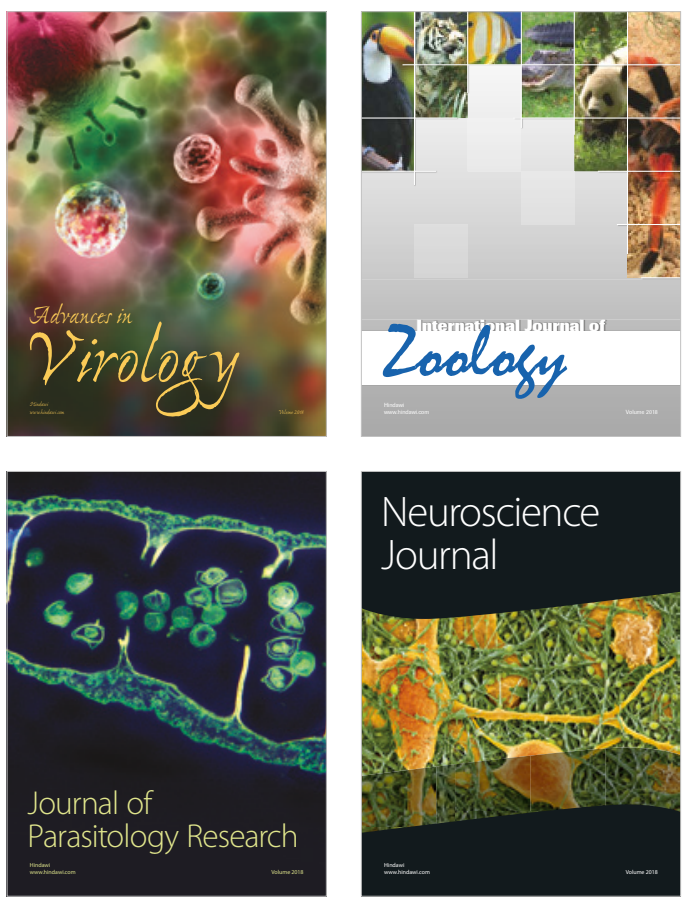
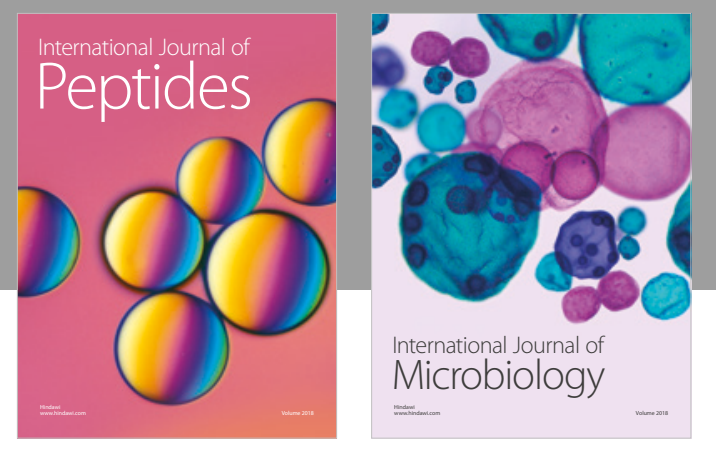

nternational Journal of Microbiology
Journal of
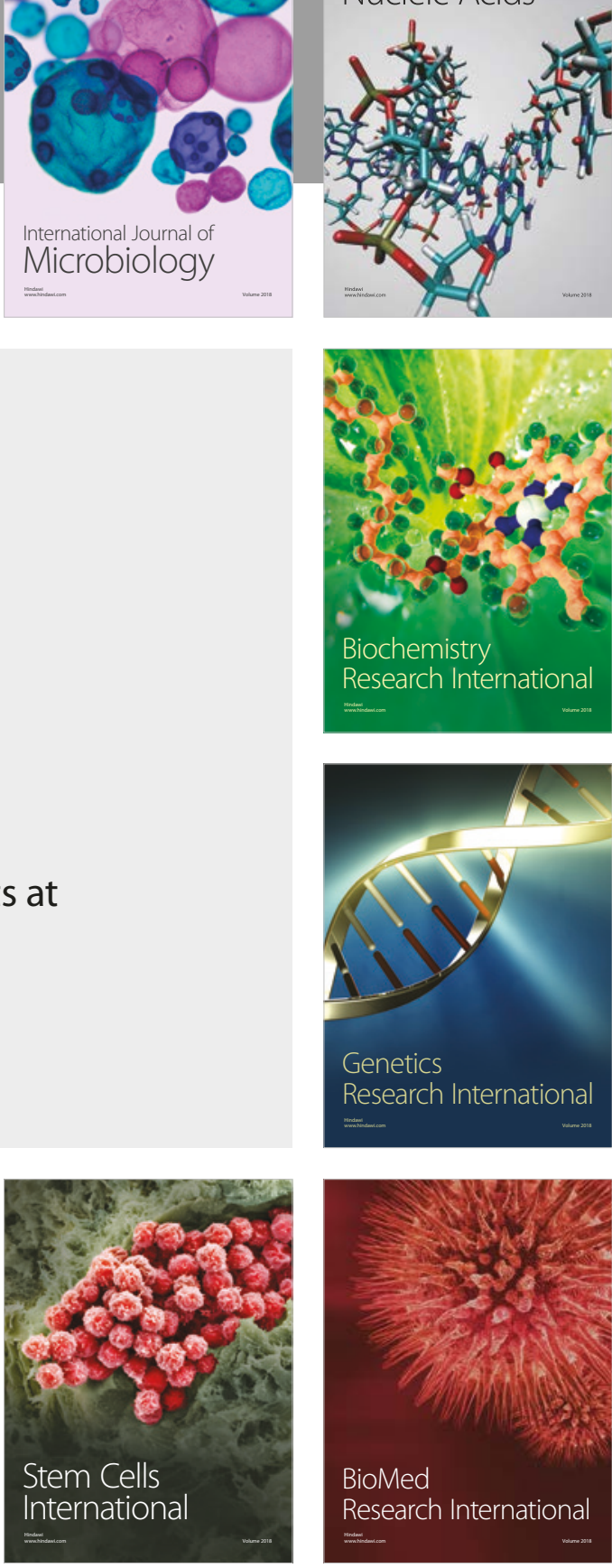
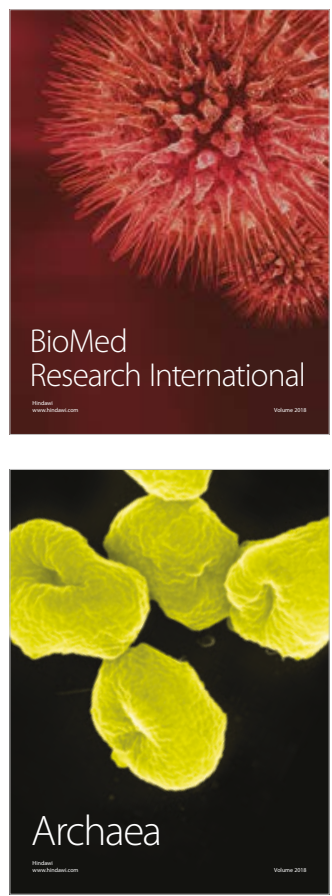